Portland State University

PDXScholar

5-7-1979

\title{
Cultural Values, Educational Methods and Small Group Communicator Styles in the United States and the People's Republic of China
}

Lynda Lee Densem

Portland State University

Follow this and additional works at: https://pdxscholar.library.pdx.edu/open_access_etds

Part of the International and Intercultural Communication Commons, Social and Cultural Anthropology Commons, and the Speech and Rhetorical Studies Commons

Let us know how access to this document benefits you.

\section{Recommended Citation}

Densem, Lynda Lee, "Cultural Values, Educational Methods and Small Group Communicator Styles in the United States and the People's Republic of China" (1979). Dissertations and Theses. Paper 2764.

https://doi.org/10.15760/etd. 2760

This Thesis is brought to you for free and open access. It has been accepted for inclusion in Dissertations and Theses by an authorized administrator of PDXScholar. Please contact us if we can make this document more accessible: pdxscholar@pdx.edu. 
AN ABSTRACT OF THE THESIS OF LYNDA LEE DENSEM FOR THE MASTER OF ARTS IN SPEECH COMMUNICATION PRESENTED MAY 7, 1979.

Title: Cultural Values, Educational Methods and Small Group

Communicator Styles in the United States and the People's Republic of China

APPROVED BY MEMBERS OF THE THESIS COMMITTEE:
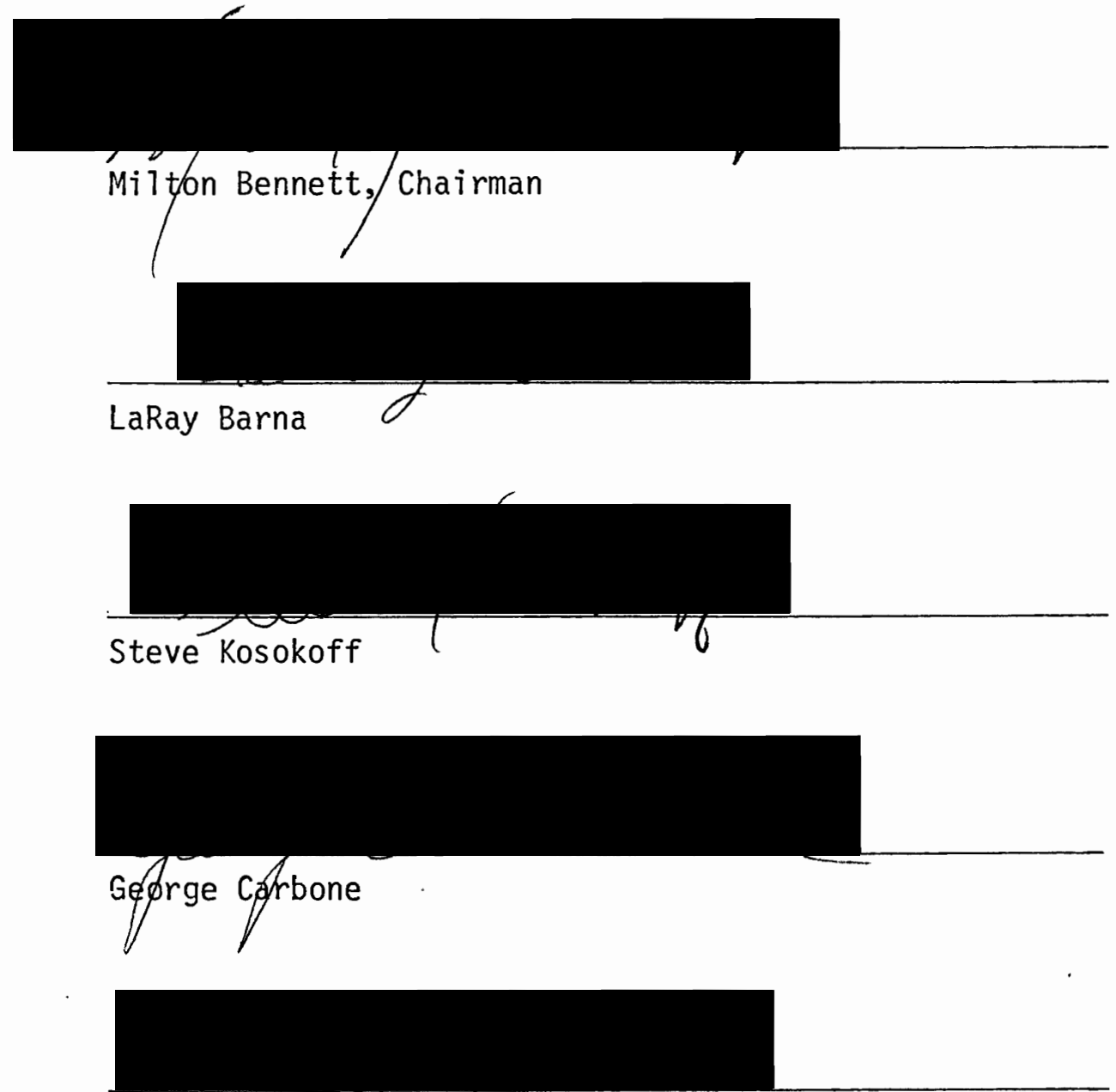

Carol Burden 
ABSTRACT

The increasing contact between countries in today's shrinking world indicates an urgent need for effective communication between cultures. Fundamental to satisfying this need is an understanding of cultural value systems--what factors have created them and how they interact within society. This paper addresses the value systems of two countries that recently have found themselves in positions of expanding contact, the United States (US) and the People's Republic of China (PRC). The value systems of the cultures are traced from their transferrence to the young of the cultures through formal educational systems to their effect on learning and perceptual sets. General implications are then suggested as to the effect of these learning and perceptual sets on the communicator styles of the cultures when meeting in a small task group settịng.

Two basic premises of this paper are that culture is learned and that thị learning process, referred to as "deutero-learning," or learning to learn, by Bateson (Ruesch and Bateson 1968), affects the way in which all other stimuli are received and interpreted. Expectations regarding these stimuli form learning and perceptual sets that influence communication behaviors.

A synthesis of research indicated that the people of the PRC historically and presently place a high value on the concepts of collaterality, or "groupness," and cooperation. These cultural tendencies are reflected in a variety of educational structures and processes, 
which, for the purposes of this study, were classified into five categories: "group identity," "social responsibility," "authoritarianism," "conflict avoidance," and "regulation."

It was shown how these teaching structures and processes helped form in the Chinese student cooperative and conformant perceptual and learning sets. Such sets may be revealed in small task group communication behaviors such as an interdependence of group members, a concern with formality and procedure, a polychronic time orientation, a strict adherence to group norms, minimal overt displays of emotion or censure (as manifested in a concern for "face," indirection and compromise), directive leaders, a centralized communication pattern, a conformant decision-making process, an efficient problem-solving approach, and a high dependence on context for the interpretation of messages.

A review of literature indicated that individualism and competition are two pervasive and strong values in the majority culture of the US. These tendencies are at least partially a result of educational approaches which can be categorized thus: "self-orientation," "individual flexibịịty," "democracy," "confrontation," and "critical thinking."

These teaching structures and processes lead to an individualistic and competitive "set" that may be revealed in the following small task group behavioral characteristics: a stress on organization, task accomplishment, and democratic group organization and leadership; a monochronic, or linear, time orientation; a lack of commitment to group objectives; a quantitative approach to solutions; an analytical, somewhat creative approach to problem-solving; and outspoken, aggressive and superficially gregarious oral communications. 
It is suggested that when the two task groups interact, one may begin to overcome resultant communication blocks through an empathic awareness of the problem differences--what they are and why and how they operate--and a willingness to switch from one's own frame of reference to that of another in order to better interpret and work with those cultural differences. 


\title{
CULTURAL VALUES, ĖDUCATIONAL METHODS AND \\ SMALL GROUP COMMUNICATOR STYLES IN \\ THE UNITED STATES AND THE \\ PEOPLE'S REPUBLIC OF CHINA
}

\author{
by
}

LYNDA LEE DENSEM

\section{A thesis submitted in partial fulfillment of the requirements for the degree of}

\author{
MASTER OF ARTS \\ in \\ SPEECH COMMUNICATION
}

Portland State University

1979 
TO THE OFFICE OF GRADUATE STUDIES AND RESEARCH:

The members of the Committee approve the thesis of Lynda Lee Densem presented May 7, 1979.
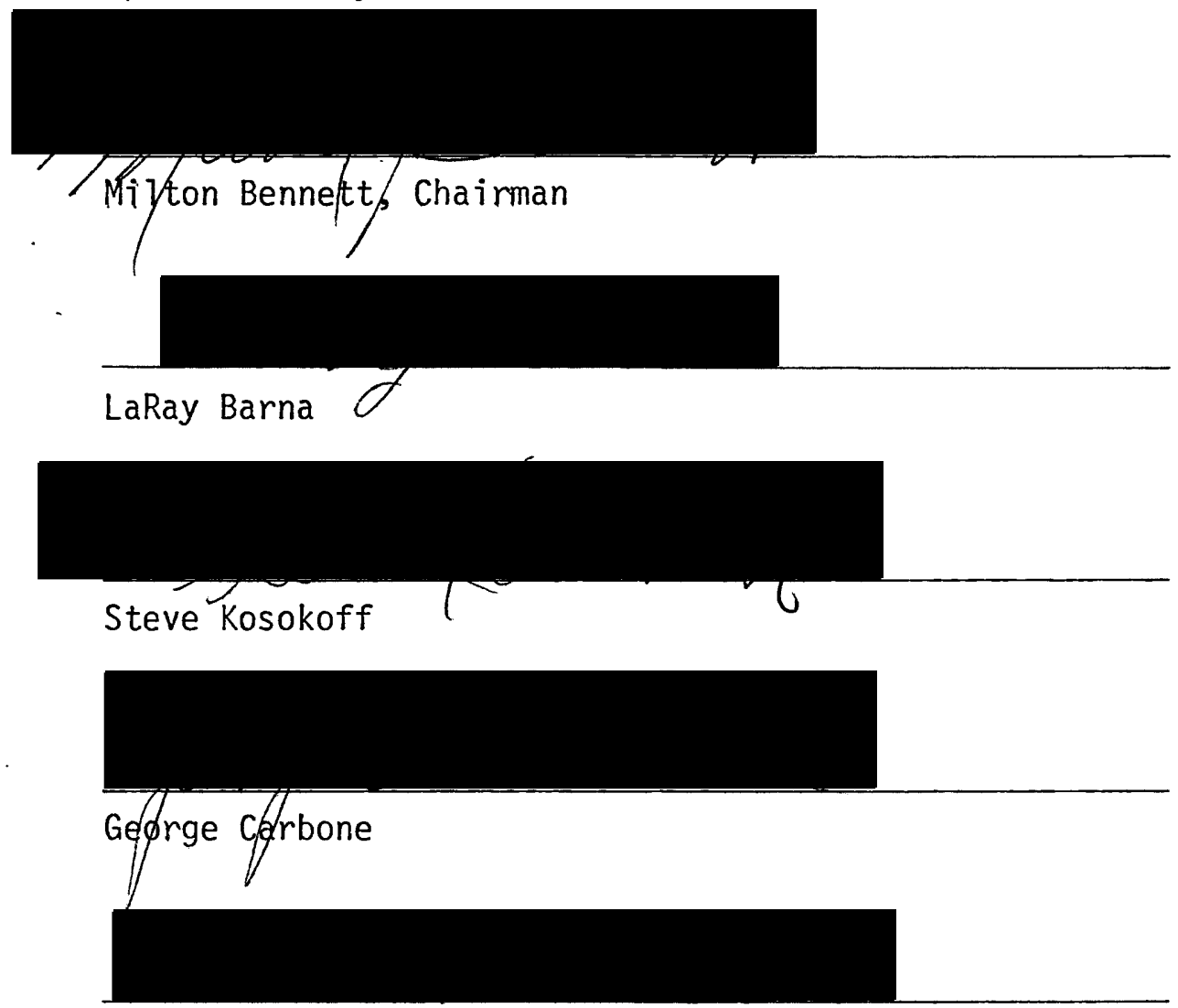

Carol Burden

APPROVED:

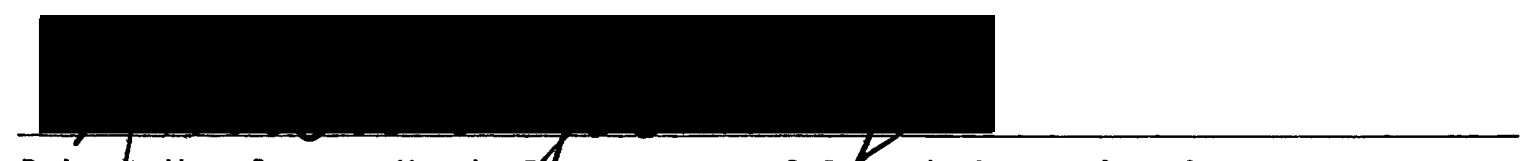

Robent Vogelsang, Head, Jepartment of Speech Communication

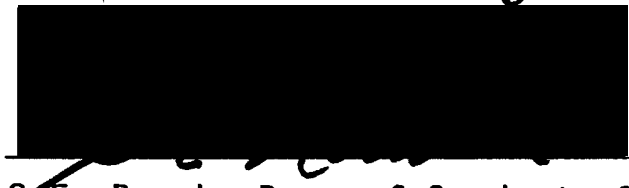

S.E. Rauch, Dean of Graduate Studies and Research 
TABLE OF CONTENTS

CHAPTER

PAGE

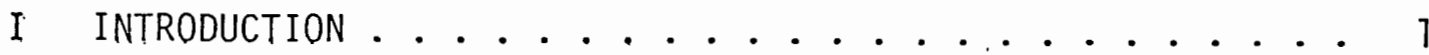

II DESCRIPTION OF TOPIC ............... 7

III THE LEARNING PROCESS ............... 11

IV CHINESE AND AMERICAN CULTURES:

A HISTORICAL PERSPECTIVE

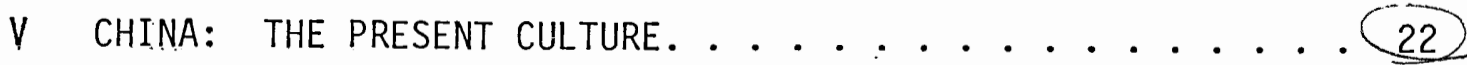

VI CHINA: THE EDUCATIONAL SYSTEM . . . . . . . . . 26

VII CHINESE EDUCATION: THE RELATIONSHIP

OF CULTURAL VALUES TO LEARNING

SETS AND PERCEPTUAL SETS ............. 31

Group Identity . . . . . . . . . . . . 32

Social Responsibility. . . . . . . . . . 36

Authoritarianism . . . . . . . . . . 39

Conflict Avoidance ............. . . 47

Regutation .............. . 43

Conclusion . . . . . . . . . . . . . . 49

VIII THE US: PRESENT SOCIETAL VALUES

AS A REFLECTION OF THE PAST. ........... 51

IX THE AMERICAN EDUCATIONAL SYSTEM. ........... 54

$X$ AMERICAN EDUCATION: THE RELATIONSHIP

OF CULTURAL VALUES TO LEARNING

SETS AND PERCEPTUAL SETS ............. 57

Self Orientation............. 58

Indivịdual Flexibịlity . . . . . . . . . 64

Democracy. . . . . . . . . . . 67 
CHAPTER

PAGE

$X$ (cont.)

Confrontation . . . . . . . . . . . . 70

Crịtical Thinking... . . . . . . . . . . . . 71

Conclusion. . . . . . . . . . . . . . . 75

XI COMMUNICATOR STYLES OF THE CHINESE

AND THE AMERICANS IN A SMALL

TASK GROUP SETTING . . . . . . . . . . . . . . . . 76

Operating Variables. . . . . . . . . . . . 78

Structural Variables . . . . . . . . . . 81

Interactive Variables. . . . . . . . . . . 86

XII SUMMARY AND CONCLUSION. . . . . . . . . . . . . . . . . 94

Summary. . . . . . . . . . . . . . . . 94

Conclusion . . . . . . . . . . . . . 97

Suggestions for Further Research . . . . . . . . 99

SOURCES CONSULTED . . . . . . . . . . . . . . . . . 102 


\section{CHAPTER I}

\section{INTRODUCTION}

The increasingly interactive quality of cross-cultural relations in today's politically, economically and socially animated world cannot help but finally turn attention towards the often ignored need for effective intercultural understanding and communication. It has long been recognized that there are differences between cultures that can critically impede peaceful international relations; it has only been in the last few years, however, that the voices of those who study the communication processes operating in such circumstances have been heard, thus granting the study of Intercultural Communication the recognition it deserves as an essential element in world affairs.

The process orientation of Intercultural Communication separates this field from those more widely recognized cultural disciplines which emphasize content. The latter describe the products of cultures, while Intercultural Communication examines how those products and other variables interact when representatives of two or more cultures attempt to communicate. The factual knowledge provided by content-oriented courses is certainly an integral aspect of intercultural understanding, but alone it is ineffectual; when applied through the techniques of Intercultural Communication, however, facts become part of a dynamic process that, through awareness and empathy, works to overcome intercultural barriers. Society is slowly awakening to the need for this process-oriented approach to cultural interaction. 
The fact that the United States has recently recognized the People's Republic of China (PRC) has given additional urgency to the need for greater intercultural awareness: a new chapter has been added to the massive volume of foreign lifeviews and lifestyles which Americans must learn to understand. Given the pervasive nature of America's potential transactions with the PRC--political, economic, educational and social--it is important that not just government representatives, but all Americans be aware of the process of effective intercultural communication.

To understand the active process of intercultural communication, one must first be aware of the passive factors that influence it, i.e., values. Knowledge about one's values, which are defined as "preferred channels of communication or relatedness" (Isenberg 1972, p. 8), is necessary for the interpretation of messages. Without this knowledge, the process of communication stands the risk of being superficial and ịneffective.

Although it is generally accepted that value systems are learned, rather than inherited (Ruesch and Bateson 1968; Krech, Crutchfield and Ballachey 1962; Rosenthal and Zimmerman 1978), the focus of this precept has been on the content of the learning experience. There are some, however, who advance the theory that it is not so much instructional content that matters as it is the actual learning process. Gregory Bateson, in Communication: The Social Matrix of Psychiatry, promotes just such-a theory and creates the term "deutero-jearning"--Jearning to learn $=$ to identify it:- He suggests that there is a

set of formal categories for describing character structure, and these descriptions are derived not from what the subject has learned in the old simple sense of the word "learning," but from 
the context in which the simple learning occurred (Ruesch and Bateson 1968, p. 217).

He states that it is the structure of learning that molds our thought processes, thus our valuing processes. In the American and Chinese societies, where formal education fills a major portion of a person's developmental years, much of what happens in terms of value formation takes place in the context of the school. Education, then, becomes a purveyor of the value system from which communication behaviors are drawn.

This paper will attempt to demonstrate how the process of formal education acts as an agent in the transmission of societal values to the individual by facilitating the formation of value-oriented perceptual and learning sets, as described in Bateson's deutero-learning theory. Emphasis is placed on this aspect of the paper because of the important role it plays in understanding the intercultural communication process. Further, this paper will touch upon how, once these sets are formed, they may influence interaction patterns in small task group settings. Both areas wi11 be examined within the contexts of the present general cultures of the US and the PRC. The paper will conclude by suggesting a few intercultural communication blocks that may result from the difference between value systems and thus learning and perceptual sets of the two cultures. It is hoped that such information will provide information for a better understanding of the two cultures and that the processes described herein will be generalizable to an awareness of value acquisition and transmission in other cultures as well.

Communication patterns in the small task group setting were selected for this study in order to isolate the information on value-oriented perceptual sets and their corresponding behaviors into a relevant and 
workable environment. A task group is here defined as "a group that is confronted with a stimulus situation in which the group is held accountable for some outcome such that their behavior is subject to assessment against specifiable criteria" (Berg and Bass 1961). Since much of the initial interaction between the US and the PRC is most likely to take place in such a setting--i.e., business meetings to determine contracts and policies--and since behaviors found in the task group environment may often be indicative of typical reactions in other situations, formal or informal, it was felt that this framework would have generalizable import.

The fact that this paper discusses only majority characteristics in both cultures should be emphasized. Recognizing that there certainly will be exceptions and variations to the tendencies described herein, thịs paper necessarily is concerned with those characteristics which, over time, have shown themselves to be consistently and comprehensively representative of the cultures. It is also important to keep in mind that many of the characteristics assigned to each culture in this paper may be shared by the other culture as well, with the difference being primarily one of degree.

Innumerable studies have been done on the small task group intercation process; the Western world abounds with theories and observational techniques in this area, giving emphasis to the sometimes fanatical Occidental preoccupation with the values of work and action. The literature available on the more passive Oriental culture holds less concrete evidence on the subject. Consequentry, most of the ideas suggested in this paper are the result of synthesizing specific, observable phenomena with abstractions. This is accomplished by describing cultural 
generalities about the target countries and by applying to these generalities the findings of studies which suggest related behavioral tendencies. Because of the subjective nature of such associations, many of the conclusions, especially those dealing with the PRC, invite additional testịng.

Although not plentiful, research relating to the basic part of this study (i.e., the effect of education upon perceptual set) is more readily available. Primary among those to venture theories on this subject is, of course, Gregory Bateson. His Social Planning and the Concept of "Deutero-Learning" (1942) and "Cultural Determinants of Personality" (1944) bring out many points that demonstrate the effect of deutero-learning upon culture. Bateson states, for example, that in Tearning experiments it has been found that an individual learning to recite nonsense syllables not only learns to repeat the nonsense syllables, but, correspondingly, becomes more skilled in the process of learning nonsense syllables. Utịifing various learning theories, Bateson shows how each educational process promotes perception and interpretation of the environment in a manner which is characteristic of the process itself: Pavlovian learning subjects, for example, will learn to expect a world in which they will have no control over the good and evil which befall them. Bateson illustrates this theory in the processes of rote learning, instrumental avoịdance and many others (Ruesch and Bateson 1968). Supporting Bateson's theory is John Martin Rich, in his book, Humanistic Foundations of Education. In this book, Rich suggests that the process through which students learn the basic beliefs and modes of behavior of their culture may be actually part of the teaching process. The deutero-learning theory has also been advanced, although not so 
named, by H.E. Harlow (1949) in his learning set curve, which, Bateson suggests, is really a deutero-learning curve. 


\section{CHAPTER II}

\section{DESCRIPTION OF THE TOPIC}

This paper basically utilizes three levels of reference: the indịịdual, the group and the cultural environment. It demonstrates the influence of each level on the others, progressing from the larger sphere of environmental influence on the value structure of large groups (i.e., the educational system) to the effect that these group value systems have on the individual's perceptual set. Finally, it examines the effect that this perceptual set has on the interaction patterns of the small task group and how these patterns may influence intercultural communication between American and Chinese groups.

The term "culture," as it will be used in this paper, refers to a process, or activity, not a static entity. It is defined as the "sum total of the ways people pattern their functions into conduct and more specifically transmit these patterns to their children (Kluckhohn and Murray 1949, p. 115). Patterns refer to shared concepts and forms of social and work interaction (Roberts and Akinsanya 1976).

Basic to the thesis of this paper is acceptance of the idea that culture is learned, not inherited. Studịes have shown that children's early development and social contacts play a large part in determining the way they will use and eventually refine their means of communication. Jurgen Ruesch states that "Man's account of the world is acquired through social interaction and communication, and those acquired views are the foundations upon which will rest the future organization of his 
surroundings" (Ruesch and Bateson 1968, p. 35). Supporting this idea is the study by Kluckhohn and Murray (1949) that showed that cultures vary in their response to the environment, thus providing learned values for behavion goals. It has been shown several times over that social setting plays an important role in the interpersonal traits of group members.

Once it has been established that culture is basically learned, the next step is to determine the context in which it is learned. Given that humans are essentially gregarious, it is natural to find them gravitating towards groups to meet their social requirements. Groups fulfill three important categories of needs for human beings: the need for sociability, the need for security (i.e., the sharing of aims, thoughts and actions, sympathy and support) and the need for status (Hsu 1970). In order to satisfy these needs, large portions of time must be spent interacting in group situations.

If such large amounts of time are spent in various group settings, it naturally follows that groups would have a great influence on the character formation of the individual. The group is the primary source of the values and attitudes important to the maintenance of social order (Krech, Crutchfield and Ballachey 1962). Through group conformity pressures, humans learn early in life those attitudes and values which will bring them acceptance in society (Shepherd 1964).

The type of group to be examined for its effect on the transmission of societal norms and values is the group other than the family that probably plays the largest role in influencing value formation--the educational structure. A11 human societies rely greatly for their survival upon accumulated learning (Kluckhohn and Murray 1949). Without it, there would be no perpetuation of culture. Everything one is and does 
is modified by the process of learning, which, for most developed countries, takes place mainly within the context of formal educational structures.

Once behavior characteristics, habitual responses and interaction patterns are learned, they gradually sink below the surface of the mind and are anchored in the depths of subconscious perception. Many of the most important paradigms or rules governing behavior function below the level of consciousness; covertly influencing behavior (Hall 1977). This subconscious patterning is responsible for what is referred to as selective perception, or the tendency to pay attention to specific stịmuli based on past learning and experience (Rosenfeld 1973). Generally, those qualities which have been emphasized in the learning situation will be perceived more readily. Selective perception determines cognịtive systems (Krech, Crutchfield and Ballachey 1962), which, in turn, determine behavior. This idea is succinctly expressed in the Chinese dictum, "Thought determines action" (Yu 1964).

In contrast to the educational group, which will be examined for the influence it wields on the individual, the task group will be examined for how it is influenced by the individual. The culturally influenced perceptual set that each individual brings into a group situation is manifested in his or her communicator style. The communicator styles relating to the task group include several variables: interactive variables, such as problem-solving skills and the ability of group members to work together; structural variables, such as communication and attraction networks; and operating variables, such as procedures, roles, norms and standards under which the group operates (Rosenfeld 1973). All of these will be considered in this paper's review of small task 
group interaction patterns.

In summary, it is the intention of this paper to describe the basic cultural values and norms of the societies of the PRC and the US; to demonstrate how these cultural values and norms are transmitted by the formal education systems of these two countries; to examine the relationship between these systems and the formation of perceptual and learning sets in the individual; to relate these sets to some typical behaviors of each culture in a small task group situation; and, finally, to suggest a path towards an awareness and understanding that may lead to overcoming some of the resultant communication difficulties. Such a project covers a large territory. This, plus the hypothetical nature of the paper, excludes it from the realms of scientifically defined validity. Scientific validity, however, is not its goal. Rather it is the goal of this paper to synthesize diverse pieces of information into a subjective analysis that may suggest areas for further, empirical research. 


\section{CHAPTER III}

\section{THE LEARNING PROCESS}

As stated above; culture is learned. It could also be defined as learned and shared behavior. The shared values of a society are transmitted to its children through a process of exposure and reinforcement known as "acculturation". (Rich 1971). Many studies have been done to show the presence of acculturation in the perceptual, and, thus, learning, process: Malinowski (1923) and Seligman (1901) were two early theorists who supported the idea that perception is influenced by culture. Another pioneer, Slosson (1899), demonstrated the importance of group suggestion on perception. Later studies (Bartlett 1932; Ichheiser 1949) support this idea by demonstrating the influence of social factors in perception. It is fairly well established, therefore, that culture determines which drives will be gratified and which will be suppressed or sublimated (Rich 1971).

Basic to an understanding of the system of perceptual acculturation is a clarification of how the learning process works as a reinforcement tool for the perpetuation of cultural norms and values. Children's awareness of their environment and the strategies they use to collect, process and interpret information are primarily drawn from exposures to the behavior patterns of the people around them. They learn to abstract the common themes underlying actions by others in the culture, later using these themes as frameworks in which to organize their knowledge and guide their behavior (Rosenthal and Zimmerman 1978). In societies where a 
significant portion of children's lives is spent within the walls of an institution of formal education, it follows that a significant amount of these learned themes of knowledge and behavior would result from the stimuli of such an institution.

What are these stimuli? Certainly the teacher is one, both as a purveyor of material and as a role model. The modeling effect of a teacher or other influential person within the school environment encompasses many perceptual levels, spanning the distance from the overt to the covert. As Edward Hall said in Beyond Culture (1977, p. 212),

Opportunities for learning about the cultural self occur at all levels, ranging from the details of pronunciation of language to largely dissociated or poorly developed parts of the personality, the way people move--their tempo and rhythm--the way they use their senses, how close they get to each other and the type of bonds they form, how they show and experience their emotions, their images of what constitute maleness and femaleness, how hierarchical relationships are handled...

In role modeling, the effect of a teacher is for the most part passively imitative. Although the importance of imitative learning in the acquiring of social behavior has been established (Miller and Dollard 1941), the active learning process is of equal, if not greater, importance. Process--defined as "a function of change in the relationship between variables" (Kimbal1 1976, p. 269)--can be demonstrated in a great number of teaching maneuvers, each consisting of a cluster of acts designed to secure certain learning outcomes. These clusters, or learnịng styles, include rote learning, Pavlovian learning, and instrumental reward and avoidance. Hall (1977, p. 190) refers to the structure of the educational process and how it molds our thought patterns by stating that "Educatịon influences mental process as well as how problems are solved." John Martin Rich (1971), Solon T. Kimball (1976) and many 
others, too, have emphasized the importance of the actual process of learning to the perception of cultural experiences.

What happens, then, once these imitative and stylistic stimuli are presented to the student? The complicated process of perception takes place. Perception has been defined as an experience which is occasioned by the stimulus of one or more of the sense organs and influenced by the reinstatement of the effects of previous stimuli (Dennis 1951). This definition of perception, along with another which explains it as an "adaptive" and "regulatory" process (Gibson 1969, p. 119), paves the way for the aspect of perception relevant to this paper--its selectivity. Eleanor Gibson, in Principles of Perception (1969, p. 119), says that

perception is not passive reception, it is active search. From the welter of stimulation constantly impinging on the sensory surfaces of an organism, there must be selection... Perception ...focuses on wanted stimuli and rejects the rest.

In other words, the perception process "picks and chooses" those stimuli most acceptable and understandable to the receptor.

Causes of selective perception range from the need for stability of the perceptual world to the need to achieve immediate clarity and definiteness in one's apprehension of objects, even though the cues furnished are ambiguous (Hilgard 1951). Both of these needs--but especially the former-are exemplified in the effect that groups have on perceptual choices: in Group Dynamics (Cartwright and Zander 1968) it was stated that membership in a group determines many of the things an individual will see, hear, do, learn and think about. It was also shown that people remember material that supports their own point of view much more completely and accurately than they retain information that attacks their point of view. Each of these phenomena demonstrates a tendency to gravitate towards those 
stimuli that maintain a status quo, thus contribute to stability of perceptual responses.

The implications of selective perception within the realm of the educational group are several: in the struggie for continuity and stability in stimulus responses, most individuals will hold fast to the notion that all other individuals think and remember in the same way they do. This idea serves to perpetuate teaching modalities and, hence, cultural proclivities, for teachers who make such an assumption will naturally promote in their teaching styles and content those ideas which are most consistent with their own perceptions. It has been demonstrated that teachers tend to perceive students with their own cognitive style more favorably than those who differ from them (DiStefano 1970). It would follow then that those students who expressed learning styles consistent with those of the teacher would be positively reinforced; they would be encouraged by the teacher to act in such a way that would serve to perpetuate the ideas set forth by the teacher, who in turn is influenced by the policies of the institution.

Although there wi1l be those teachers who deviate from the cultural norms and who, therefore, further anti-cultural forms of behavior and cognition, the majority of teachers are themselves products of an educational institution of culturally established norms and would, perhaps unknowingly, tend to serve as perpetuators of those norms. Here it should be stressed that it is not the purpose of this paper to propose that people are mere automatons who act and react in ways prescribed and demonstrated for them by others, but to point out the influence that prescribed forms of perception and behavior have on the individual and the society as a whole. Institutional reinforcement practices and peer 
usage norms have important effects on the development of scholastic behavior (Rosenthal and Zimmerman 1978).

Because perception is selective in nature, it not only makes us perceive things in a certain way, but it also makes us expect to perceive things in a certain way (Wenburg and Wilmot 1972). This is demonstrated in the "halo effect," or the tendency of one's general observations about someone or something to influence his or her specific impressions (Thibaut and Kelley 1959). This idea further magnifies the role of the educational process in influencing students' perceptions: students who accept the authority of the educational institution will be more likely to accept the values that it promotes. Even those who rebel against that authority cannot help but be in some way influenced by it.

The interrelatedness of perceptual sets to learning sets is important to the theme of this paper. Psychologists have long used learning sets as an explanation of perceptual selection. A learning set, once formed, largely determines the nature and direction of stimulus generalization (Harlow 1949). The individual is said to have learned when dịscriminating reactions as well as anticipation of events indicate mastery of the subject (Ruesch and Bateson 1968). Bateson explains how subjects of a particular learning experience are correspondingly influenced in their perception and interpretation of the world: subjects with repeated experience in instrumental contexts will expect the world to be made up of contents appropriate for instrumental responses; Pavlovian subjects wịl learn to expect a world in which they will have no control over the good and evil which befall them; subjects with repeated experience in instrumental avoidance will have an appropriate orientation, different from that of the subject with experience in instrumental reward. 
A learning set, like a perceptual set, is an established predisposition towards a certain stimulus response. Where a learning set differs from a perceptual set is in its application: a perceptual set deals with different types of stimuli, while a learning set is concerned only with those stimuli affected in a learning situation. Learning sets are tools of the mind that allow it to learn how to learn (deutero-learning) in sịtuations frequently encountered (Harlow 1949). They allow the individual to adapt to a changing environment not through trial and error, but by

hypothesis and insight, changing learning problems from intellectual tribulations into intellectual trivialities and leaving the learner free to attack problems of another hierarchy of difficulty (Harlow 1949, p. 56).

They are the means through which the human race has been able to adapt and survive.

Research focusing on cognitive sty.le has shown the relationship between cultural values and the development of learning sets (Witkin 1967). It has shown that cultural values are reflected in socialization practices which, in turn, affect the development of cognitive styles in children. A study by Ramirez and Price-Williams (1974) related this concept to field independent and dependent cognitive styles: it demonstrated that field independent cognitive styles are more common in cultures characterized by formally organized family and friendship groups, and field dependent cognitive styles are more typical in students reared in cultures with shared function groups. This dichotomy will be addressed later in this paper when discussing the differences between group-oriented and individualịstic societies.

Other authors and researchers also support this point of view--i.e., 
that cultural values and cognitive styles, thus learning sets, are closely related. Eleanor Gibson (1969, p. 132) shared this opinion when she saịd, "The habits and attitudes characteristic of one's culture... have a selective effect in determining what one attends to..." Segarl, Campbell and Herskovits (1966) claimed that perception is inferred from habits built up through repeated impressions derived from the environment. Once the influence of cultural values is felt in the classroom, it does not stop there. The learner, thus "indoctrinated" and set to receive and interpret information in a certain way, will experience a world in which previously established propositions seem to be verified, therefore reinforcing his or her own belief. The deterministic limitations enforced by deutero-learned premises make it possible for the individual to perceive in his or her own idiosyncratic manner, which reinforces deuterolearned premises. This premise, or belief, in turn determines the phenomena of human relationships (Ruesch and Bateson 1968).

The area discussed above will not be related to the specific cultural tendencies of the PRC and the US. This paper will demonstrate how the educational systems of each of these cultures are reflective of basic cultural values and how these values are perpetuated in the educatinal setting through the formation of perceptual and learning sets as discussed above. 


\section{CHINESE AND AMERICAN CULTURES:}

A HISTORICAL PERSPECTIVE

In describing the Chinese and American cultures two dominant and dịstinguishing characteristics emerge--the qualities of individualism and collaterality, or "groupness." The US epitomizes the Western world's preoccupation with individual worth, while the PRC is rooted in centuriesold reverence for the group-oriented way of life. -To understand the impact of these two qualities on the cultures they embrace, it is advantageous to view them first from a historical perspective.

The Western world has long been known as a culture steeped in the ideal of individual importance and self-expression. Initiative, achievement, aggressiveness, and activity are synonymous with especially the American image of the individual. This concept contrasts sharply with Eastern phịlosophies and lifestyles, which emphasize a merging of individual wịl and spirit with the needs and wants of the group. As Westerners tend to be active, Easterners tend to be reflective; as Westerners support the concept of individual value, Easterners have found value in conformity (GuTick 1962).

The Western ideal of individual worth is basically an outgrowth of Christianity (although it could be argued that Christianity is a product of emerging individualism if one were to accept the idea that it is not religion that creates ideals, but ideals that create religion). Alexander Woodsịde, in Vietnam and the Chinese Model (1971, p. 15) stated it thus: 
The whole attitude to action and achievement which characterizes Western Civilization is rooted in the tradition of Christianity. Western man has tended to imitate his omnipotent God, and has sought to be both legislator over society and master of the natural laws which govern the physical world.

Western Judeo-Christian tradition conceptualizes a god who stands apart from his creations. Such a division cannot help but encourage notions of autonomy. This dissociation of God and His creations is aptly illustrated in the Biblical account of the great flood, where God demonstrated Hịs alienation through the destruction of all creatures except those He chose to save. This is but one of many examples within Christian doctrine of the evocation of individual power and will.

The Eastern culture, on the other hand, reflects a religious or moral tradition that cultivates the ideal of merging the individual will and identity with a greater force. The principles of Confucianism pervade much of what has been passed down from generation to generation. They form the basic moral fiber of the present Chinese culture, even in the PRC where communism has attempted to temper this centuries-old doctrine. The Confucian ideal of an innate, hịerarchical structure in society served to encourage in the Chinese personality an already present disposition towards subservience.

The isolationist history of China--a result of a geographical location that barricaded it on three sides with the mountains and the sea and, later, on a fourth side with the Great Wal1--created a culture relatively uncontaminated by foreign influences. This resulted in both a collective sense of self-sufficiency and an often disastrous impoverishment in the area of technological advancement. The latter left the country helpless agaịnst national calamitịes, especially Chịna's longtịme mortal enemy, the flood. The usual after effect of such catastrophes, 
poverty, became endemic and combined with other social conditions (Gamberg 1977) to become a part of a vicious cycle which left destitute Chinese resigned to a life over which they wielded little control (Danton 1938).

This sense of fatalism was intensified by the caste-like social system that immobilized Chinese society. Those who engaged in manual labor, the only field of work available to the poor masses, were considered to be on the lowest rung of the social ladder, and there was little hope for change. For the majority this intrinsic inferiority necessitated an attitude of fatalism. There could be no such thing as the concept of individual identity and spirit so valued by the the Western cultures: one's identity must melt into the collective personality of one's peer group, and one's will must acquiesce to that of the group in power.

The only escape from such a powerless existềnce was a strong sense of spiritualism. The religious beliefs of Buddhism, Taoism and other Eastern religions emphasize harmonious relationships among all living things. Joseph Needham, in Science and Civilisation in China (1954-1976, p. 323), expressed his belief that the origins of Chinese fatalism were to be found in such religious beliefs:

The harmonious co-operation of all beings arose, not from the orders of a superior authority, external to themselves, but from the fact that they were all parts in a hierarchy of wholes forming a cosmic pattern, and what they obeyed was the internal dictates of their own natures.

God was seen as an impersonal force, whose dictums, like those of mortal powers, were to be accepted as part of the natural order of the universe. God, as conceived by the Chinese, was quite unlike the JudeoChristian God, who existed as a separate entity from the people on whom he exercised His witl. Such a stance would be unthinkable in the 
Chinese religion where the pattern of mutual dependence extended from humans to gods (Hsu 1970). There could never be a division of church and state such as that found in the US (Woodside 1971).

Because of a culturally ingrained sense of external control and because of the geographically and socially imposed need for self-sufficiency, the Chinese found security in the small group structure. Selfsufficiency had become a frame of mind, but even under such dictates, one could not hope to survive entirely alone: there was a very undeniable need for the bonding that could be found in the small group situation-a primary group that would serve as a protection against the individual and the inequities of a rigid, hierarchical society (Hsu 1970). The solidarity of human relationships within the primary group became the fundamental impulse of the Chinese. Beyond this structure there was little of importance: historically in China there was seldom a sense of patriotism or involvement in causes that went beyond the primary group. A Chinese maxim exemplified this feeling: "Sweep the snow in front of your own dwelling, but don't bother about the frost on the roof of other homes" (Hsu 1970, p. 354). 


\section{CHAPTER V}

\section{CHINA: THE PRESENT CULTURE}

A historical perspective of the Chinese culture is important to the topic of this paper, but the era of primary concern is the present. The traditions of the past must now be applied to the realities of China's present societal situation.

After the Communist Revolution of 1.949 , it would appear that China's society had undergone a marked change. The Revolution, the result of a series of Chinese responses to the Western impact that had victimized China since the middle of the 19th century (Hsu 1970), seemed to be a head-on confrontation with the Confucian ideals that had dominated the society for so long. Confucianism came to be regarded as the enemy of progress--progress towards a communistic egalitarianism, a leveling of the hierarchical society of the educated elite, the privileged.

Mao Tse-tung, leader of the Revolution, believed that through conscious action people do not have to be slaves to objective reality: they can create their own reality (Gupte 1970). This would seem to be in direct opposition to the traditional Oriental philosophy of fatalism and obedience to external forces. Was this, however, actualiy a conflict, or, rather, a new face for an old idea? It is a basic premise of this paper that many traditional Chinese values have not been eradicated since the Revolution, but, instead, re-directed to the advantage of the new society. The ideals of the Revolution are consistent with the Chinese sense of collaterality and fatalism in that the socialist philosophy of the PRC 
is rooted in collaterality and the maintenance of this philosophy is dependent upon the re-education of the people towards a new community mentality (Gamberg 1977) that may utilize societal proclivities towards fatalism and acceptance of authority in the realization of this goal. The clan structure sanctified by Confucianism still stands as a somewhat invisible, but powerful, force under China's socialism (Cressy 1957). As previously stated, historically the members of a clan had a strong sense of social responsibility--but only to members of their own clan. Mao sought to redirect this reliance on and servitude to the family towards a similar allegiance to the state (Isenberg 1972). The strength of traditịonal family allegiance was diluted by separation: while employment outside the family was once discouraged, such employment was now not only encouraged, but mandated. As family members dispersed, the state began to assume the familial role. Child rearing and education, moral instruction, protection and nourishment--all formerly functions of the family or the clan--now became the province of the state, accompanied by the same allegiance once enjoyed by the family alone.

How did the government manage to sustain this almost sudden switch from a situation-centered family structure to commitment to an allencompassing state ideology? It has been said that in order for a group to sustain itself long enough to fulfill socio-emotional needs, tasks must be selected that give the group a definite, concrete purpose (Hall 1977). The maintenance of communist ideology became that purpose and, in turn, became self-perpetuating: as the government succeeded in fulfilling the survival needs of the people, providing adequate food and shelter, not to mention a new self-esteem for the members of the former Tower classes, the survival of such a system became a reward and a purpose 
of its own.

The traditional Chinese tendency towards acceptance of external authority was also instrumental to the purposes of their leaders. The years of Confucian influence had generally accustomed the populace not to question authority. "Free thought," which flourished in other, more urban societies, had had no nourishment in the fragmented, agrarian Chinese society. Economic factors made it necessary to perpetuate such rural naiveté through the establishment of decentralized factories and work farms. Respect for authority was a necessary ingredient in the organization of a society in which the government must demand strict obedience from its people. Class structure was-re-established in a new form, with two main divisions--those who ruled, the communist leaders, and those who obeyed, the people (Nakamura 1960).

The concept of authoritarianism is related to that of collaterality in the Chinese society: the group becomes the authority. Group pressure is frequently used as a method of societal control. If a group member-whether of an educational group, work group or community group--does not fulfill his or her responsibility to the group or to the society as a whole, other group members take it upon themselves to pressure the deviant member until compliance is given. An example of this is seen in the story of a man in the PRC who was reported not to be using birth control devices, much against the wishes of his wife and the suggestion of the state. Upon hearing that the wife's pleas to her husband were being met by deaf ears, a Women's League group took it as its social responsibility to correct the situation. One by one they visited and cajoled the husband until he finally broke down in exasperation and promised to fulfill his dutịes as a good husband and a responsible citizen (Myrdal 1965). The 
needs of the group had taken precedence over the desires of an individual.

Some may wonder how the Chinese were able to accept communism so quickly, with comparatively little resistance. This could have been possible because the Chinese by nature have traditionally accepted strong sțate power (Nakamura 1960). But perhaps it also is related to their situation-centered way of life and the value placed on mutual dependence and conformity. The long-standing social approval enjoyed by these qualities may explain why the Chinese have never had any significant struggle for individual liberties, and, at the same time, have not felt any need to persecute those who have differed from them (Hsu 1970).

The death of Mao in 1.976 signified the end of the Cultural Revolution that had epitomized the most recent years of socialist rule. The emphasis on survival that took precedence during his administration is being shifted to an emphasis on modernization. The Chinese are now slowly breaking their long pattern of isolationism and self-sufficiency and have declared themselves ready to join the industrial nations of the world (Newcomer 1978). With the normalization of relations between the US and the PRC, the door to change now seems to have swung wide open. The "Great Leap Outward" may lead the way towards a westernization that will influence and alter the traditional value system. Where Mao used the cultural traditions of the society in the promotion of the communist system, the present government may be leading the nation away from such traditions. What this means in relationship to the characteristics of collaterality and authoritarịanism discussed above remains to be seen, and for that reason this new direction will not be a consideration of this paper, which will focus primarily on Maoist influences in the Chinese society. 


\section{CHAPTER VI}

\section{CHINA: THE EDUCATIONAL SYSTEM}

It has already been established that a society's educational system is reflective of its values. It is not surprising, therefore, to find that the PRC's utilization of communal tendencies for communistic ends also exists in its educational community. For many years the purpose of education had been to teach and promote Confucianism. The Revolution sought to eradicate the educational elitism of Confucianism and to focus the primary attention of education on the changes necessary to the promotion of a communist society (Tregear 1973). Mao believed that only through collectịve effort and will could the old traditions be broken. And, given the fact that Mao's policy was to educate the $80-90 \%$ of the population that was illiterate prior to the Revolution, the role of education in the implementation and exercising of this collective will was great. Adding strength to this role is the fact that it is possible and not uncommon for a child's educational experience to begin as early as 56 days of age: in the cities especially, women workers are given two months maternity leave from their jobs, after which time they may put their babies into state-run nursery schools at the factories where they work (Kosokoff 1978). The impact of such early and widespread education can be formị dable.

In order to accomplịsh such a massive societal reorganization, it is necessary to completely eliminate the old ways and being anew. As an old Chịnese proverb says, "If you do not destroy, you do not build". (Chu 1977, 
p. 178). To make these changes, schools were shut down for several years at the beginning of the Revolution. During this time there was a purging of those teachers. whose Confucian tendencies proved too deeply ingrained and a re-education of those who could be changed. Teachers were to be given the additional role of partners with the students, rather than purely that of authoritarian leaders, as before. This new partial egalitarianism was somewhat due to a realization by the Communist leadership that as long as teachers remained in a position of absolute authority, new belijefs and values would be difficult to establish (Chu 1977).

Revolutionary reorganization also meant the rewriting of teaching materials. A1l references to Confucianism were eliminated and textbooks were rewritten to complement the communist government's pragmatic approach to education. The only knowledge that was acceptable was that which could serve as a guịde for practical experience and that which arose from such experience (Lehmann 1975); knowledge for $i$ ts own sake was of no value (Chu 1977). Overly complicated academic materials were avoided. Informatịon was honed down to the most essential elements--"Less but essential," as Mao put it (Lehmann 1975, p. 74). Mastery of selective knowledge was thought to be more important than superficial acquaintance with large quantities of facts (Chu 1977).

The school was seen as a training ground for leaders "who could till the land with their hoes, criticize the capitalist class with their pens, and defend socialism with their guns" (Lehmann 1975, p. 159). That this should be an element of the educational system was not viewed as a contradiction between the rights of the individual and the claims of society in a land where individualism had always given way to collaterality. 
After the initial reorganization of education, the cultural themes promoted by the government through the schools varied in tenor with the times and with the philosophies of the incumbent leaders. 1958 saw the true beginning of Mao's stress on the combination of school and work, or "Open Door Schooling" (Peking Review 1978). From first grade on students were expected to alternate their classroom education with a certain amount of time in socially productive activity--work in the factories and the fields. Pragmatism took precedence: schools would often close, for example, in order that students might help with the harvest. In the effort to combine theory and practice, the humanities were to view society as a factory (Lehmann 1975). The expected impact of the environment on the students' development is reflected in a saying borrowed from the Chin Dynasty (280-430 A:D.), "Something that is near red dye becomes red; something that is near black ink becomes black" (Chan 1976, p. 16).

To further prevent the re-emergence of an educational elite, students from the former lower classes were given preference in admittance to colleges and the specialized training schools that were once the sole province of the wealthy. These steps were taken to eliminate all vestiges of the previous hierarchical structure of society and to aid in shifting loyalties from family and clan to the state (Kosokoff 1978).

In the $60^{\prime} \mathrm{s}$ there was a creeping re-emergence of the former bourgeois ideals. It was alleged that the educational institutions were accepting too many students from middle class families (Maskerras and Hunter 1968). In 1966, for example, $9.4 \%$ of the university students were from such families (Kosokoff 1978). This served as an impetus for the Cultural Revolution that took place between 1966 and 1969. During this time schools were once again closed for reorganization, students and faculty alike being: 
sent to the fields and the factories instead. During their stay, teachers were expected to learn from the experiences of the workers and, with the workers' guidance, to prepare new, more practical teaching materials. The focus was to change from the traditional dependence on texts to that of practical experience (Chu 1977). When texts were necessary, each district was to write its own, relating them to local conditions and problems. These texts often would be used for years, then criticized by students and rewritten (The Committee of Concerned Asian Scholars 1972).

The 1970's saw the influence of the Gang of Four, the four under Mạo (including his wife, Chiang Ching) who were said to have surreptitiously usurped his power. During this time the Gang of Four succeeded in eliminating many of the theoretical aspects of education and redirecting educational efforts towards purely political ends. They had an extreme contempt for any hint of bourgeois character in education. They were opposed to promotions and exams, regarding them as tools of suppression and control for the elite. They spread the idea of anarchism among the students and labeled all teachers as "bourgeois intellectuals," preferring an uneducated worker to an educated exploiter (Kosokoff 1978). Mao's death precipitated a purging of the government: the Gang of Four was thrown from power and, once the dust settled, a new leader and a new form of government had emerged. Those now in power acknowledged the "tumble-down state" of Chinese education--finding, for example, only about 630,000 university students in a population of one billion and set about to rebuild the educational strength of the schools. The government reinstated the admission exams that had been dropped in 1966, infusing them with a new rigor and uniformity (Time 1979). Elite schools were 
established, with the best teachers and facilities. Ranks and titles among teachers, which formerly had been dropped, were restored, and salary increases were reinstated as an added incentive towards quality instruction. They ordered a stress on teaching basic theories and updating the sciences. Students could now take exams, and, if they passed, could skip ahead several grades (Peking Review 1978). These represented elements of Confucianism which were once again establishing a foothold in the Chinese educational system.

What the future holds under China's new leadership, one can only guess. But, again, this paper will only concern itself with those characteristics of Chinese society which dominated up until this most recent reorganization. Even those changes presently being made by the new government, however, must, as all before them, derive strength from those cultural traditions so deeply rooted in a history of collaterality. 


\section{CHAPTER VII}

\section{CHINESE EDUCATION: THE RELATIONSHIP OF CULTURAL VALUES TO LEARNING SETS \\ AND PERCEPTUAL SETS}

The learning and perceptual sets fostered by the process and structure of the Chinese educational system may be classified into four general areas, which, for the purpose of this paper, shall be called "group identity," "social responsibility," "authoritarianism," "conflict avoidance," and "regulation." "Group identity" refers top the merging of self-boundaries with those of the group; "social responsibility" alludes to the expansion of group boundaries to include all of society; "authoritarianism" describes relịance on external control; "conflict avoidance" expresses an emphasis on nonaggression and harmonious interpersonal relationships; and "regulation" explains the acceptance of uniformity and methodical control. Each of these categories represents, through the processes and structures utilized in the educational system, the projection of a current and historically established value into the individual's value system and, ultimately, back into society's value structure.

This next section of the paper will examine those educational structures and, especially, processes which encourage and sometimes create perceptual sets and learning sets indicative of a culturally accepted value system. - Each area dịscussed is intricately interwoven with the concept of collaterality. 


\section{GROUP IDENTITY}

As has already been stated several times in several ways, the importance of the group is supreme within the Chinese culture. Taken one step further, it can be said that the Chinese believe i.t to be an act of selfishness to consider oneself before the needs of the group (Gamberg 1977). The Chinese 1anguage aptly mirrors this cultural dispositịon towards selflessness: for example, in country districts the phrase "How do you do?" translates lịteral7y into "Have you eaten your rice?" The usual reply is translated as "I have been so selfish," reflecting the fact that the mere act of satisfying one's hunger may be considered selfish, since it may deprive someone else of their food (Danton 1938, p. 20):

Group affiliation begins early in a child's formal education. Since millions of Chinese women work, their children's early years are mostily spend in day-care centers, where they are toilet-trained, cared for and taught (Isenberg 197.2), conditioning them from the beginning as to the importance of survival within a group situation. Those very formative pre-school years which, under the individualistic American system, would normally be spent building the child's concept of self, are instead spent building the child's concept of others, the self being seen only as it relates to the group.

These Chinese preschoolers spend most of their day in group activities, such as singing, exercising, playing games, dancing and putting on performances (Gamberg 1977). Even the limited amount of academic work they do is done within the group context: the group works as a team to solve each problem, with each young student striving to 
help the others. There is here, as later in life, a spirit of mutual participation in the learning process. There is no sense of a "smarter one" or a "dumber one"--no teacher's helper. Each student is taught to share in the failures or successes of the others. An example of this is found in the behavior of a group of kindergarteners struggling with a new math concept. One boy who was called on to solve a problem for the class repeatedly gave the wrong answer. No one giggled or smirked, and he showed no embarrassment about his errors. Finally the teacher asked the group to help him, which they did, displaying no attitude of "one upmanship" (Chan 1976). Such an absence of competitiveness is present even in sports activities, where the general motto is "Friendship first; competition second" (Kosokoff 1978). The self, then, as viewed by Western cultures, does not even exist. The boundaries of ego and personality extend beyond the individual to the affiliative group.

This sense of collaterality is strongly promoted through the nonverbal structures in education. Classroom organization usually takes the form of students sitting in neatly ordered rows facing the teacher (Gamberg 1977), giving them a sense of identity with the masses--a perception that will serve to promote harmonious existence in their socialistic society.

Another way in which the group concept takes precedence over the individual is in the reward system utilized by the schools. Status, in the form of good work reports and praise, is like most other communistic ideas, achieved through group affiliation. Students who do their best are praised as good group members (Hevi 1963). This does not mean that there are no individual assessments. Students who do especially well in their studies are singled out for praise, although such praise is directed 
towards their contributions to the group rather than to themselves.

Students who do not do so well, instead of being punished with bad grades, become the recipients of special attention given by all the groups with which they interact-school, family, and even neighborhood (Kosokoff 1978). Those who deviate only s7ightiy may be given the opportunity to correct themselves; in a fourth grade.class recently observed learning to make steps for a bus, a chịld decided to try making his steps differently from the way he had been instructed. Instead of being reprimanded or corrected, he was allowed to continue and make his own mistakes, the teacher's phịlosophy being that gradually he would learn to trust the years of experience the teacher had (Rosenthal and Zimmerman 1978).

Teachers are considered to be moral guardians as well as instructors, personally approaching and coaxing those students who need additional help in any area, personal as well as educational (Maskerras and Hunter 1968). This, of course, results in the students' having very little privacy, but privacy is not an important aspect of a group-centered way of Tife.

Groups, then, must share responsibility for any individual failures and, therefore, are required to make an effort to rectify the situation. A slogan created by the Red Guard expressed it thus: "Do not let a single student lag behind". (Kosokoff 1978).

Just as the group takes responsibility for the performance of the individual, the individual is expected to take responsibility for himself or herself. "Self-criticism" sessions have become an integral aspect of the Chinese system. These sessions are held on a regular basis, and are not just Timited to educational groups. Each member is expected to openly admit to and criticize some aspect of his or her behavior. Many 
of the areas criticized relate to some failure in one's duty towards either the small group or society as a whole. Here individualism does play a part: students are often seated in a circle during the session so they can look each other in the eye as they are singled out for their failures--indịidual failures, yes, but still failures in relationship to their group responsibilities." Each student. is expected to give as well as receive criticism (Yen 1954). They are even encouraged to criticize the teachers, who, after al1, are basically just other group members (Maskerras and Hunter 1968). The system involves the use of praise first, then criticism, thus helping to avoid the loss of "face," a very important aspect of communication that will be more fully discussed later in this paper (Yen 1954).

The effects of such self-criticism before the group are to heighten conformant tendencies. Students learn through such an approach that every aspect of their behavior is open to group scrutiny and, perhaps more important, self-scrutiny in front of the group. A learning set is formed in which all stimuli are responded to in relationship to how they would be perceived by the group. The group has somewhat taken over the function of perception through this automatic perceptual process.

Experiments have shown that such social pressure on perception can cause misperception of reality (Chu 1977). When the general climate of a group-is one of attack on deviancy, conformity tendencies are likely to be increased (Krech, Crutchfield and Ballachey 1962). The greater the individual's knowledge of the group, the more exact will be the approvalseekịng dịrectịon of each group member (KTein 1956).

As the self is merged into the group, individual need achievement becomes correspondingly lower, having merged with the needs of the group. 
It has been shown that the lower an individual's need achievement, the greater probạbility that the individual will conform to group norms. A study by Faust (1959) supports this idea by demonstrating that group members with a high need for affịliation conformed more to a particular view, even when there was no support for that view.

It seems evident, then, that one resurt of the perceptual set of group identification cultivated wịthin the Chinese educational system is a tendency towards conformity. Conformity--defined by Webster's New World Dictionary as "the condition or fact of being in harmony or agreement"r-is also an essential ingredient in the cooperative behavior that later wịl be shown to typify Chịnese interaction patterns.

\section{SOCIAL RESPONSIBILITY}

Sma1.l group perceptual patterns are carried through to the larger, societal level through an emphasis on social responsibility. The Chinese are educated to serve their people, not their own self interests. This process begins as early as kindergarten: they are taught revolutionary songs and a dislike of imperialism as a method of binding them together in a loyalty to the "state group." Texts are censored and have been rewritten with a Marxist bias, even novels. A chemistry text may defịne matter by beginning, "Lenin says," followed by what Lenin considered to be a correct definition--one which may conflict greatly with the commonly accepted Western definition. Social consciousness is considered the most important criterion for admission to universities (Hevi 1963). (This may be tempered somewhat by Chịna's recent push towards new excellence in educational standards.) Students are assigned various courses of study according to the state's plans, not their own 
inclinations (Kosokoff 197.8). The state's needs take precedence over the students' needs all along the educational path.

From a very early age students are given social responsibilities that would seem inappropriate to Westerners--labor and military exercises (The Committee of Concerned Asian Scholars 1972). Their school lessons are geared to confirm the values of the society. (NBC 1979). In them they are taught that their first loyalty is to the state, which, after all, has taken over the educational function that once belonged to the family, so why not receive the loyalty that once was the sole province of the famity (Cressy 1957)?

Even as early as nursery school and kindergarten children are taught the supreme importance of the state. They are encouraged to become members of the patriotic "Little Red Guard." In elementary school they may become "Little Red Soldiers," Tater going on to be full members of the patriotic arm of the communist government, the "Red Guard" (Isenberg 1972). Through singing and dancing to patriotic songs and putting on plays that teach patriotic morality, they learn the role that the state is to take in their lives. Games are even couched in political terms: Tosers are often chided about being "imperialists." Through such methods children internalize the spirit of the struggle necessary to Qvercome the past (The Committee of Concerned Asian Scholars 1972).

The curriculum reflects this political emphasis. An example of studies in the primary school would be courses in politics, Chinese language, physical culture, math and revolutionary art and culture. After fifth grade they may have courses in English and "common knowledge," which includes mechanics, agricultural studies, and natural science. The theory and methodology learned in these courses are geared towards 
application in school workshops ard gardens (The Committee of Concerned Asjan Scholare 197.2).

A variety of interactive styles is used in the classroom to promote in the students this sense of socịal identity. Matêrial is often analyzed from a political standpoint, no matter what the subject matter of the material. Language courses, for example, emphasize not only the mastery of the target language, but the political content of the language. Such analysis does not take the form of a free analysis that might give rise to criticism of the state, but interpretations are kept within the boundaries of those patriotic attitudes expected by the state (Lehmann 1975).

Nonverbal symbols that glorify the state abound in the classroom, as el sewhere, forming a very important aspect of teaching strategy. Pictures and posters of political leaders stare from the walls of each classroom, perhaps mingled with a few red posters with sayings of Chairman. Mao on them (Lehmann 1975).

Exams are even used with the state in mind. Whereas they had been declared "irrelevant" before the Cultural Revolution, they are now accepted as important tools for reviewing knowledge of and adherence to the rules of social responsibility (Kosokoff 1978).

Although some dịsension is allowed, most young Chinese still feel it is too dangerous to strongly question the politics of their state; yet Chịna is not wịthout ịts dissịdents. One student dissident summed up the situation thus: "We are compelled to believe (Marxist-Leninist) theory and we do not observe our life and society from our own point of view... Many of my friends do not like to study society and our life (Seattle Times 1979). It would seem, then, that the development of 
societal norms has, for the most part, taken place at the expense of critical expression. The more these norms and values are internalized, the less possibility there is for individualistic philosophies to develop.

Such selective exposure reinforces the learning set that is established on the small. group level discussed earlier, except that now the concept has been stretched to include a larger. group. The societal values of conformity to group standards would seem to be once again confirmed. This group identity is further encouraged through outgroup conflict: i.e., the presentation of other societal value systems as a threat to the Chinese society. Conflict with other groups contributes to the establishment and reaffirmation of the identity of the group (Coser 1956). And the more this group identity is solidified and group membership valued, the more resistant to external contrary persuasion the group members become (Campbe11 1961). It is a self-perpetuating cycle.

\section{AUTHORITARIANISM}

The acceptance of the state as an authority higher than the individual is both a result of and a reason for the strong sense of fatalism in the Chinese character. It follows that from this should arise in the student a highly "other-directed": learning set. Just as students accept the authority of teachers, they react similarly towards government officials and all others in positions of power. It has been said of authoritarianism that "Since the human network is seen as the principal avenue for dealing wịth one's problems, authority and exploitation tend to escalate themselves from which the individual can hardly extricate himself" (Hsu 1970, p. 385). This concept is certainty true in the 
Chinese society, where the cultural ideals of reciprocity and dependence (i.e., father supports son, son supports father) is ingrained in the culture. There is a definite vertical orientation in the chinese culture: as the child grows up, elders are always to be looked up to and obeyed (Hsu 1970). Because of such values, the Chinese regard relationships with fellow human beings, rather than control of things, as the principal avenue for the solution of life's problems.

To the Chinese a sense of security is gained from submission to authority (Chu 1977). Decisions have usually been made by someone higher in the chain of command--from parent to teacher to government. Citizens are expected to conform to the decisions of their leadership, and institutions are designed to support this system (NBC 1979).

The educational institutions are not the least among such support systems. Although there is a feeling of groupness and interchange in the classroom situation, the teacher remains in a position of authority, in turn answering to the authority of the government. There is generally a discouragement of individua thanking, logical reasoning or creative thinking (Hevi 1963), all of whịch have the potential of fostering ideas unsupportive of society's needs. Once again the societal value placed on conformity is promoted through the educational system. The Tearning set thus established carries through into the students' daily lịves. Those in positions of power who are viewed as competent and worthy of respect evoke among others a conformant behavior (Steiner and Peters 1958). Those with titles will elicit similar behaviors (Barry 1931), thus the power of Chaịman Mao, Vice Premier Deng and others. Strong leaders who evince feelings of their being intelligent, strong, successful, and of high status will certainly induce more conformity than their lower 
status subjects (Harvey and Rutherford, undated; Lefkowitz, Blake and Mouton 1.255). The more of an orientation an individual has towards such authority, the more he or she is predisposed towards conforming behavior (Rosenfeld 1973). Historically, such subjugation of self to authority has contributed to the capacity of the Chinese character for tolerance and patience when in situations of stress and for acceptance of hard work (Chu 1977),

\section{CONFLICT AVOIDANCE}

The tolerant Chinese personality affects the teacher-student relationship in a way that further promotes cooperation. Through a patient, positive approach, the teacher is able to effect a harmonious classroom atmosphere, thus creating a set of expectations in the student which dictate that learning--and, therefore, other life activities--should take place in such an atmosphere. Learning, like the ancient ideats so ingrained in the Chinese personality, is not separate from, but in harmony with, life.

Educators promote this harmonious learning atmosphere through teaching techniques which emphasize positive behavior in the students. They expect good behavior without denying the possibility of negative behavior. When such behavior does occur, other students join the teacher in an attempt to persuade the errant student to use reason in dealing with the situation. Aggression towards others is not considered healthy, and for this reason aggressive behavior is rare (Chan 1976).

Such a. nonaggressịve, positive approach to classroom instruction finds its roots in the Chịnese concept of "face." Face may be loosely defined in Western terms as dignity and respect, but it is a term not so 
easily defined. Loss of face may be caused by being too blunt in one's approach, not using the proper sense of indirection. "Courtesy," said a Chinese student in defining the term in a psychological test, "is telling a lie to save the feelings of others" (Danton 1938, p. 122). In a culture where courtesy has come to be a matter of such great importance, it is easy to believe that unpleasant truths should be suppressed in the interest of social harmony (Guljck 1962). A less than courteous statement may lead to a direct action, which, in turn, drives the parties involved into a corner and causes inevitabilities (Danton 1938). If one avoids such reactions in the first place, face is retained and the basically passive Chinese character has not been forced into disagreeable action.

Expediency also plays a role in classroom harmony. This concept, too, finds its roots in an ancient Chinese philosophy--that which says there is a definite connection between the end desired and the means employed (Nakamura 1960). Truth and what Westerners may call ethics are considered by the chinese to be relative to pragmatic action. The way the Chinese see themselves in this respect has been described thus: "What I am concerns only myseif, what you think I am is of little importance; what is current between us is an idea of what I am, is sufficient for the traffic of the day" (Danton 1938, p. 122). There is no universally accepted morality, then, except that which serves the purpose of the task at hand. This idea is perhaps a cousin to the old maxim that exhorted the Chinese to sweep the snow off his own roof and not to worry about his neighbor's roof.

The result of expediency and face in forming student perceptions is one of unity with the whole--collaterality and cooperation. Students who 
are taught to avoid conflict in the classroom will apply this avoidance to their outer environment. Students who are concerned with loss of face will not argue with the teacher and not expect to argue with other persons of authority on the oustide. A harmonious learning atmosphere seems to have the effect of producing hardworking, enthusiastic students, devoid of cyricism and arrogance and insatiable. in their curiosity (Maskerras and Hunter 1968).

Studies have shown that the longer a group remains together and at a particutar task, the higher the probability of its success, and in such situations a high level of arousal could actually interfere with some task completion (Davis 1969). If the results of such studies are applied to the Chinese learning set of harmonious interaction, one may conclude that without such arousal the group's cohesion would be high and task completion a greater eventuality. Aga in the aspect of cohesion, thus cooperation, is seen in the Chinese value system.

\section{REGULATION}

A basic need of a totalitarian society like that of China is control. The government must be able to direct the thoughts and, therefore, behavior of the governed. Control is best maintained when there is uniformity of ideas, which, in turn, is best obtained when there is a basic uniformity of activities. To initiate such uniformity in the society there must first be a leveling, or equalizing, of the class structure; then, to maintain this uniformity, deviations from the norm must be dịscouraged, producing an overall similarity of experiences.

The educational system seems once again a prime vehicle for such societal rehabilitation. But to justify such a procedure in the Chinese 
society, the basic goals of education first had to be changed. The past emphasis on education as a means to improve one's social position would not do in the new egalitarian society: therefore, the intellectual pursuits of history, literature, and the arts were sublimated to the practical skitls needed by society. The purpose of education in China today is not to gain power, but to work for the good of the people (The Committee of Concerned Astian Schotars 1972).

Just as society was to be rid of classes and divisions among people, so was the educational structure. There was an all-out attempt to equalize education (Kosokoff 1978). All classes of people were provided an education, wịth special attention being given to the previously ignored lower classes. To facilitate this, the number of required attendance years was cut from 12 to 10 , and the tracking system encouraged by the former school entrance exams was temporarily abolished (The Committee of Concerned Asian Scholars 1972). There was even equalization between the sexes: boys are now encouraged to try traditionaliy "feminine" pursuits such as needlework, and girls, conversely, are encouraged to delve into traditionally "male-oriented" fields such as the sciences (Kosokoff 1978). There is lịttle segregation of fast and slow learners (Chan 1976). Bright chịdren are encouraged to live up to their capacities, but not at the expense of their classmates. Chinese children are told that it is more important for them to learn to love and respect their peers than to think of themselves as special, and individual capabilities and talents are valued only for what they contribute to the group. As previously mentioned, the traditional exaltation of the teacher is discouraged and the teacher is given more direct responsibility for and to the students. The result of this amalgamation is a heterogeneous mixture in the schools 
(The Committee of Concerned Asian Scholars 1972).

Once leveling has taken place, regimentation must keep the levels equal. One way in which this is achieved is through the use of rigid formalities within the teaching structure. An orderliness prevails throughout the classroom: bells regulate the class periods; students stand up when the lessons being (Maskerras and Hunter 1968); students are often required to answer teachers inquiries by raising their hands and standing to recite their answers (NBC 1979); welcoming ceremonies are given for new students. In learning about the hardships of the old society, often individual students will give formal testimonies about those days (The Committee of Concerned Asian Scholars 1972). And regimentation is even found in the students' social lives, where marriage is dịscouraged before college graduation (Maskerras and Hunter 1968).

Another way in whịch the students are regulated lies in the teaching process. Much of the old-fashioned use of rote learning and reciting still remaịns (Isenberg 1972). Typịcal classroom procedure may involve straight lectures and repetition in large group situations (The Committee of Concerned Asian Scholars 1972), with 7ittle debate or discussions (Chu 1977). Imitation and repetition are primary learning tools in the Chinese educational system.

The Chinese language complements this rote learning tendency, for to become proficient in Chinese one must memorize a great number of indivijual characters. Although the communist party reformed the language to simplify and reduce the number of characters, to be literate one must memorize and be able to recognịze at least 1500 characters, to be fluent, 5000, and the total numbers above 10,000. Only the grammar remains simple, with no declensions or conjugations (Hevi 1963). 
Al1 of thị is certainly amenable to the development of a mechanical memory, an abịlity that Leninist principles decreed as essential for the transition of a people from ignorance to knowledge (Lehmann 1975). The more numerous the models of the same act, the stronger the incentive becomes for that act, which means that such repetitive learning would further encourage reliance upon rote acts outside the formal educational environment (Campbel1 1961). The lack of emphasis on self-expression not only leads Chinese children to develop a greater consciousness of the status quo, but also serves to tone down any desire on the students' part to transcend the larger scheme of things, thus status quo is maintained (Hsu 1970).

Outside of the classroom leveling and maintenance of status quo also takes place. The years that the students are required to leave the classroom for practical experience in the fields and factories play a very large role in this leveling process. The object is for the students to perceive themselves to be equal to all others, de-emphasizing the materiạ ịsm and elitism that previous ly had been encouraged through the educatịonal process (Gamberg 1977).

One of the most important characteristics of Chinese psychology is reliance on perception (Nakamura 1960). As Mao declared in his article entitled "On Practice," "If you want to know the theory and methods of revolution, you must participate in the revolution...all truths are obtained through dịrect practice" (Yu 1964, p. 25). He believed that perceptual knowledge leads to rational knowledge, basing his stance on the Leninist theory that the acquisition of knowledge is fundamentally empiricist--a notion in sharp contrast to the Confucian notion of "a priori" knowledge, or the belief that thoughts arise in the mind of a 
person prior to their being expressed in speech (Lèhmann 1975). Through actịve participation in manual labor and the resultant close interactions with the peasants, the students were expected to perceive the proletariat from a new, more realistic perspective (Chu 1977), serving to discourage their traditional disdain of manual labor.

Manual labor requirements are not necessarily favorably received by a?1. Stị1 showing past resentments, some students have been attacked by peasant groups as they go to their assigned positions. Students and their parents often wonder why they bother to obtain a formal education when they wịll only end up working in the fields. And, because the peasants for so long have vịewed education as ineffective and irrelevant to their needs, their children often do not take school as seriously as they might (Chu 1977). General7y, however, acceptance tempers any discontent (NBC 1979).

The effect that participation has on the students' perceptual set is great. In such "open systems" it is difficult for the students to perceive the boundaries of the systems--i.e., where the systems end and environments begin (Lehmann 1975). This furthers the sense of unity deeply ingrained in the Chinese culture. This sense of unity includes identity with the peasants and factory workers. The leveling of status differentiation produced by this identification prevents the lack of conformity usually present in group members who possess high social status and education (Tuddenham 1959).

It a $7 s 0$ produces a tendency to view stimuli in terms of the concrete. Here again the Chinese language works intimately with the culture, for even in the language there is an emphasis on perception of the concrete: there is an abundance of words that convey the tangible 
and inert phases of things, but few verbs expressing change and transformation. Even the expression of abstract philosophical ideas takes place in material terms (Nakamura 1960). This "concreteness" leads to a lack of consciousness of universals, for it is difficult to express general principles in specific terms.

Without universals, the applicability of knowledge is limited and it is, therefore, easier to control the amount and kind of information ayailable to the average Chinese. This control lends well to maintenance of conforming attitudes (B1ake and Mouton 1961). It has been said that the greater a person's knowledge of a. subject, the less conformant he or She will be, so perhaps it can be said that the inverse is also true--the less a person's knowledge on a subject, the more conformant he or she will become. This idea is reinforced by another study which established the fact that conformity is increased with increased control by the agent of conformity (Fearing and Krise 1941). This conformity is self-perpetuating: a study by Scott (1956) showed that the greater the number of members in a group who hold a value and the more strongly they hold it, the more important it becomes to all. It would seem that once again the ideal of conformity is perpetuated in the Chinese cultural system.

\section{CONCLUSION}

In all of the areas mentioned above--"group identity," "social responsibility," "authoritarianism," "conflict avoidance" and "regulation" --the underlying social values of cohesion and conformity surface as the driving forces behind the educational structure and process. In group 
identity it was shown how social pressure that is encouraged through a sense of groupness leads to conformity; in social responsibility and authoritarianism it was shown how the control of an authoritarian system results in conformity; in the section on conflict avoidance the result of a tendency towards nonaggression and avoidance of conflict was shown to be cohesion; and "regulation" showed how the leveling of the society and maintenance of the obtained status quo leads to conformity. These sections attempted to show how such cohesiveness and conformity are necessary to the communist philosophy, in which solidarity and advancement generally depend upon ideological unanimity (Yu 1964), and how it is up to the communication system that holds the most sway on the value development of a people, the educational system, to transmit the model with which it is expected everyone will conform.

The atmosphere of closeness or commonness of purpose defined as cohesiveness (Davis 1969) and that of the successful influence on the behavior of other persons, or conformity, lends itself nicely to Webster's New World Dictionary definition of cooperation: "to act or work together with another or others for a common purpose." Cooperation, then, seems to be the all-inclusive, general value to which the Chinese culture adheres, and, thus, the dominant theme of the communication process. The sense of collaterality which the Chinese have possessed through the centuries and have nurtured especially throughout the rule of the communist government is intricately interwoven with the resultant value on cooperation. And this value, nurtured throughout the educational process and set in the expectations of the Chinese mind, will play a very large and important role in the communication process in the small task group 
situation to be examined later in this paper. 


\section{CHAPTER VIII}

\section{THE US: PRESENT SOCIETAL VALUES}

AS A REFLECTION OF THE PAST

In contrast to the Chinese collateral concept and resultant value on cooperation, Americans in their comparatively short history have remained solidly entrenched in the Western ideal of individualism and the competitiveness it produces. The pioneers who swarmed the shores of the New World seeking freedom of expression tended to represent the most individualistic of their peers, forming a new base for the development of the self-reliant and competitive spirit that has come to symbolize America. Activity, initiative and achievement were all vital ingredients for survival in this strange new wilderness. Coupled with the already aggressive and achievement-oriented nature of the invading Europeans, it was to be expected that a newly intense version of the individualistic Westerner should evolve.

The European immigrants, finding abundance and space in their new environment, focused their attentions on coping more with nature than with theị fellow human beings (Danton 1938). In contrast to the Chinese and, most tragically, the native Americans who inhabited the land long before the Europeans, these new settlers viewed nature, like their god, as a separate force: it was there to be conquered lest it conquer them. This competition with the land left little time for the development of intricate human relationships. Niceties and formalized social rules were luxuries they felt they could not afford. 
This is not to say that there was no sense of community among these early pioneers. It was certainly necessary and desirable that they band together for mutual advantage. This kind of communality, however, was one of convenience rather than of strong commitment. It was imbued with a sense of self-reliance that would be foreign to the collaterality of the Chinese clan structure.

Most Americans speak proudly even today of the "pioneer spirit" they possess. Although there remain few wildernesses to conquer, the resourceful American has continued to challenge new frontiers in the areas of business and technology. The aggressiveness of the pioneer is transformed into the ambitions of the entrepreneur or the aspirations of the scientist. Children are still led to believe that initiative and drive are the keys to unlimited success. And ultimate success means the attainment of power--over people, things and circumstances (Ruesch and Bateson 1968). Just as the early settlers sought control over nature, the modern pioneer seeks control over a more complicated, but equally provoking environment.

The seemingly limitless potentialities existing in the rich, wide-open atmosphere of young America has led even the modern Americans to take for granted the possibilities for constant mobility. Change is perhaps one of the few "constants" of this fast-moving, flexible society. The needs of technology, fluctuating social and familial mores and two world wars have all contributed to the creation of a highly mobile society possessing little faith in stability and permanence (Spring 1978). Technological advances make it constantly necessary to adapt to a new product or a new way of living: women may work outside of the household; variations from the traditional two-parent family are not uncommon; 
once-rigid social regulations have been relaxed; and families may be scattered all over the country; at least partially because of the effect of post-war marriages between locals and transient soldiers.

This "change ethic" has permeated all aspects of American society. It has led to a disintegration of many well-established social patterns and traditions. It has lent weight to the values of adaptability, toughness, resourcefulness, self-reliance and self-centeredness. And, since the old may so easily be discarded for the new, it has become difficult for Americans to obtain a mastery of skills and techniques, to acquire information or even to clarify their own values and identities (Ruesch and Bateson 1968). Fragmentation such as this supplements an already inflated sense of individualism and competitiveness.

In order to satisfy the basic human need for emotional commitment, the individual-centered Americans turn to causes and creeds. Often these ideals are sought within the framework of social organizations and movements. Such banding together does not belie the value placed on individual initiative, for, unlike Chinese social systems which are imposed from above, American organizations usually are instigated by bands of indivịdual citizens (Hsu 1970). Once again Americans carefully guard their individualism in the face of other needs.

It is safe to say, then, that the Western ideal of individualism has survived its journey to the new American society. There it has not only flourished, but it has intensified and taken on new meaning. The historical version of the independent Westerner has become a competitive and highly self-centered American. 


\section{THE AMERICAN EDUCATIONAL SYSTEM}

As in the PRC, the educational system in the U.S. assumes a large and highly influential role in the socialization of its children. Due to the shifting boundaries of the family in American society today, the school has taken on increasing responsibility in this area (Martindale 1960). The school has in many senses become a surrogate parent, with all the accompanying ramifications: discipline, moral guardianship and guidance. It has even found it necessary to teach children skills formerly presumed taught in the home, such as grooming, cooking, and how to have a successful marriage.

The American school is also entrusted with political and economic obligations. One of the primary goals of American education is the education of future citizens, which is to be accomplished through the identification and encouragement of future leaders, the teaching of cooperation skills and through impressing on the students the importance of following rules. In the area of economics it is the duty of the educational system to promote the development of technology by training future technologists. To this end vocational guidance has in recent years taken on unprecedented importance in the schools (Spring 1978). As described by a previous vice-minister of education in the PRC, "In a capitalist country... the objective of workers' education is to increase the workers' knowledge and techniques so that they may be promoted... with better wages, positions and livelihood." He contrasted 
this objective with the Chinese educational goals of working class unity and the advancement of political ideals (Cressy 1957, p. 231). With such all-encompassing responsibilities, there can be little doubt that American schools have a tremendous impact on the values and judgments of the young and, thus, the perpetuation of an American-style value system. As previously mentioned, two of the most significant and pervasive values in this system are those of individualism and competition. How each of these is nurtured in the learning process will be described in detail in the next chapter, but it is important to note here how some relatively recent developments in American educational philosophy have encouraged the furtherance of these values.

Though much of pioneer America's schooling took place in noisy one-room schools filled with a potpourri of age and ability groups, sophistication of the country soon brought about the use of the more sedate European educational style. This approach, which consisted of rituals, lectures and was subject-matter oriented, remained the major teaching method until about the middle of this century. The societal factors mentioned in the last chapter of this paper brought about a loosening of the system: as the family relinquished more of its traditional responsibilities to the educational institutions, it became necessary for education to revamp.

Dr. John Dewey, a prominent American educator in the first half of the twentieth century, is considered the father of the child-centered approach to education made necessary by society's evolution. The tenets of Dewey's educational philosophy are: the child is more important than the subject matter to be taught; learning should be relevant and not constrained by outdated traditions; school administration should be based 
on democratic rather than authoritarian principles; discipline comes from within, not from externally imposed regulations; and experiential learning is the most effective learning style (Hsu 1970). Over the last few decades these philosophies have become firmly entrenched in American educational practices.

With the exception of the last of Dewey's precepts, experiential learning, these ideas contrast sharply with the philosophies of the Chinese educational system, where the group, not the individual child, is of supreme importance, learning styles are still somewhat traditional and authoritarianism is the ruling principle. In the chapters on the creation of learning and perceptual sets in the PRC it was shown how the related characteristics of "group identity," "regulation" and "authoritarianism" led to the perpetuation of the societal values placed on conformity and cooperation, and in the following chapters on the American educational system it will be demonstrated how the opposite characteristics, as represented by the Dewey principles above, lead to the furtherance of the American values of individualism and competition. 
CHAPTER $X$

\section{AMERICAN EDUCATION: THE RELATIONSHIP OF CULTURAL VALUES TO LEARNING SETS AND PERCEPTUAL SETS}

Just as the learning and perceptual sets produced by the process and structure of the Chinese educational system were classified into five areas, those of the American educational system fit, for the most - part, into five contrasting categories. Where the schools in the PRC encourage "group identity," those in the U.S. foster "self-orientation;" "social responsibility" in the PRC is contrasted to "individual flexibility" in the U.S.; "authoritarianism" is differentiated from the American ideal of "democracy;" "conflict avoidance" is opposite to the tendency towards "confrontation" in the U.S.; and, finally, the category of "regulation" is distinct from the American emphasis on "critical thịnking."

The American education category of "self-orientation" discusses the trend towards individual achievement, which, in turn, leads towards comparative achievement, or competition; the section on "individual flexibility" describes how this self-centeredness precludes loyalty to pervasive social and national ideals; the section on "democracy" explains how democratic ideals relate to the American preoccupation with activity and quantification; the "confrontation" passage shows how self-expression takes precedence over indirection or subtlety; and the section on "critical thinking" points out the stress put on rationality and autonomy. Each of these areas is both a cause and effect of the American value of 
individuality.

\section{SELF-ORIENTATION}

American children are encouraged in the development of selfcenteredness and independence practicaliy from the first day of life. In their pre-school years children learn from their parents to follow + their individual instincts, and membership in a group is de-emphasized in favor of individuality. American parents encourage a feeling of self-importance in their children which often serves to separate them from the reality of the world around them. Self-expression continues to be nurtured as the children enter nursery school: there, for example, they may be asked to stand up in front of the class and tell something about themselves or their activities, a technique whose purpose it is to enable each child to feel self-confident and "unrestrained by the group" (Hsu. 1970, p. 89). Throughout their school experience, these students will continue to be taught the importance of self-worth and individual achievement.

The American emphasis on the individual is so great, in fact, that often submergence of the individual personality into a group is regarded with disdain. One example of such sublimation is found in Janis' theory of "groupthink" (1971). In this theory he postulates a group culture where individual needs must fight to be preserved. The very mention of the word "preservation" denotes the desperate struggle between individualism and collaterality in the American conscience.

One manner in which this struggle is manifested is through the American concept of territoriality. From a very young age a child learns + to create boundaries to separate himself or herself from others and the 
environment. In this way the student keeps others at a distance and is safely isolated from potential "contamination" by a group-oriented way + of life. Private property is emphasized: the child speaks of "my" parents, "my" toys, "my" allowance. Once he or she enters school, the possessive will be stretched to include "my" desk. And heaven help the student who, by mistake or by design, takes a desk that has previously been staked out by another student! Even as adults, Americans will tend to return to the same seats they previously occupied and will display irritation if someone else dares to take over that place.

Such a pattern discourages physical proximity and, consequently, deters emotional and social closeness (Hall 1973).

The detachment that is fostered through territorial boundaries is also generated by the impersonality of many of the teaching techniques used in American schools. As a result of the technological bent of society, schools often resort to using machines to instruct and to motivate. Audio-visual devices have become so common in classroom instruction that most schools or districts have created departments whose sole purpose it is to implement the use of their many machines. The trend towards individualism is also responsible for this mechanized instruction technique, for one teacher cannot meet the specialized needs of each student when faced with the typically overcrowded classrooms of today: the teacher may, therefore, resort to tape recorders, viewing machines or, most desirable of all, teaching machines. Although machines may aid in the development of desired instructional skills, they also serve to further depersonalize the learning process and to separate the students from their peers. This emphasis on cognition is done at the expense of affective development (Brembeck and Hi17 1973). 
The arrangement of time is also an important factor in the development of a sense of separateness in students. The American school, like + the American society, emphasizes schedules for the completion of most tasks (Hall 1977). The school day is almost always organized into blocks of time for each activity, and whether or not the activity has been completed or learning has taken place, the students and teachers are expected to move on to the next scheduled activity precisely at the end of each time period. These time periods are often marked by the sounding of bells or buzzers, and students are admonished to promptness in heeding the dictates of these tyrranical time-keepers. The effect of this timeorientation is to subliminally support the segmentation of life. After a11, if time can be fit into neat, separate categories, so can human relationships.

Dewey's emphasis on teaching the child rather than merely the subject matter, as illustrated above, is not completely applied in the modern American educational system. The theory has produced enough of an effect, however, to have some serious implications in the development of a feeling of separate identity in the students. Teachers, either through the use of machines or through their own personal resourcefulness, general7y make an effort to instruct their students individually in order + to meet their unique educational needs. This tendency is evident in the use of I.Q. tests and in the creation of special courses and departments to work with exceptional or developmentally handicapped children. Recognizing that this segmentation does benefit students through the tailoring of education to different learning abilities, it should also be pointed out that such individualization isolates students from each other and contributes to the propagation of individualism in the American 
society (Hsu 1970).

The underlying reason for such an emphasis on individualized instruction is the basic American belief in the value of individual achievement (Parsons 1951). Such an emphasis leads to a certain amount of pressure in the learning environment: students are singled out to answer questions (Brembeck and Hil1 1973), and a student who learns fast and well is valued over one who learns slowly or poorly. The importance placed on achievement is manifested in teaching philosophies that promote activity (such as was stressed by Dewey), motivation through a rewards and punishment system, corrections and, ultimately, competition (Hall no 1973). Students learn quickly that it is those who participate and who + are assertive who will succeed in school. Such students will be the recipients of most rewards--both material and otherwise--that the school has to offer. These are the students who will most likely develop the firmest of the much-desired self-concepts; these are the ones who will become successful individuals.

Those who are not so fortunate to be bright or quick, assertive or active, are often the recipients of criticism and corrections, neither of which lend well to the development of a sense of individual worth. American teachers tend to be impatient in their corrections of students (Hal1 1973), a characteristic which contrasts sharply with the more patient and supportive group atmosphere emphasized in the PRC.

The inevitable result of this achievement orientation and resultant + status differentiation is competition (Brembeck and Hill 1973). The students' need for positive reinforcement leads them to strive for those attributes which bring them status (Ruesch and Bateson 1968). In order to ascertain those characteristics which will bring the desired 
recognition, students must constantly compare themselves to their peers (Kluckhohn and Murray 1949). Competition, defined by Webster's Dictionary as "opposition," is by its very definition a divisive factor in human relationships. The basis of competition in America is a philosophy of self-concern, for the gain of one individual means a loss for the other (Hsu 1970). This is not to say that all competition is negative; for studies have shown that when competitive techniques are employed in moderate doses, they serve to keep motivation at a high level (Klein 1956). Many accredit America's prominent place in society today to the competitive nature of its people.

This also is not to say that Americans are entirely competitive and individualistic. There exists a strange dichotomy in American ideals which says that while individual initiative is certainly desirable, the good American must also be prepared to operate as a team player (Krech, + Crutchfield and Ballachey 1962). To this latter end American children are trained to become members of teams, whether they be sports, fraternal organizations or clubs (Ruesch and Bateson 1968). The reason for such a seeming contradiction may be found in the very characteristic responsible for the competitive strain--self-reliance: with the greater freedom and social flexibility that such a characteristic brings also comes insecurity. To allay the fears that accompany insecurity, Americans have constructed an elaborate system of nonkinship associations and clubs (Hsu 1970).

Inherent in this group membership and apparent conformity is the ever-present characteristic of competitiveness. Even while Americans join groups and conform their actions to those of others, there is an undertone of competition: each person strives to do things "bigger and better" than fellow group members (Ruesch and Bateson 1968). It is arly 
through the necessity brought about by insecurity that Americans ally themselves with groups. They still prefer to win by themselves (Thibaut and Kelley 1959).

This conformity-competition paradox is manifested plainly in the educational system, where teams and clubs abound but individual achievements still gain the most recognition. Team members work towards winning the game for their school, while acutely aware that individual measurements of achievement are being kept on them as well. Students may earn a position in a "honor society" for their grades, but the achievement is accomplished for their individual recognition, not for the good of the society. There are numerous other examples of "individualistic. conformity" to be found in the American school system.

The effect that this attention on individual capabilities has on the perceptual and learning sets of the students is one that may tend to preclude classroom ethical and interpersonal development (Hsu 1970). With this low affiliative tendency there is a definite perception of oneself as alienated from and disaffected by outside influences (Rosenfeld 1973). As a result of the nonpersonal nature of instruction, as evidenced by the segmentation of time and people and the use of machines, and as a result of idiosyncratic need gratification, American students learn to view lịfe from an independent, impersonal stance (Berg. and Bass 1961). Most phenomena in nature and thought are, like the educational experience, perceived as compartmentalized and separate from their own beings.

The conforming and cooperative behavior that grew out of the Chinese feeling of collaterality can be contrasted to the individualistic and competitive behaviors fostered by the American educational process: 
A study by Grossack (1954) showed that instruction emphasizing individual achievement produced less conformity in the recipients than those emphasizing group achievement. As was discussed earlier, American instructional techniques are greatly oriented towards the individual. The very fact that American students are taught to value individual achievement is significant in the development of perceptual divergence (Grossack 1954), as is the educational stress on self-concept and self approval (Moeller and Applezweig 1957). A number of other studies also point to the effect individual achjevement needs and values have on lowering conformant tendencies (Crutchfield i955; Nakamura 1960; Tuddenham 1959; Krebs 1958; DiVesta 1959).

To say that the result of the American educational process is a perceptual and learning set geared away from conformity is to admit its counterpart, opposition, which was earlier given as a dictionary definition for competition. The competitive nature of Americans is, in turn, no more than an application of the basic psychological tendencies of American society to the education of $i$ ts children.

\section{INDIVIDUAL FLEXIBILITY}

If conformity and unity do not exist on the smaller, more personal levels of human interaction, it seems to follow that they would not exist on the larger societal level. Such is the case for Americans. The American view of commitment, whether to a small or large concern, is generally one of distaste: Americans prefer not to commit themselves to 4 any course of future action because of the handicapping effect such commitment has on individual flexibility (Ruesch and Bateson 1968). Responsibility to social goals and their concomitant organizational 
structures are regarded as secondary to individual goa.ls (Chan 1976). Just as Chinese children are immediately immersed in the social organizations whose purpose it is to raise their social consciousness, American students are generally conditioned from a very early age to view responsibility at only the personal level. From birth American children are accustomed to attaching themselves to a singular authority figure--first parents, later teachers--and, thus, they come to see only one style of life as possessing importance and validity (Hsu 1970). This is much unlike Chinese children, who may be conditioned to a multiple parental authority and, therefore, perhaps several points of view. The unilaterality of American children's concepts of authority and truth do not allow them room to embrace nationalistic concerns that may not be in agreement with their individual life views. This commitment to an individual disposition before social exposure tends to strengthen self-concern, leaving little room for other concerns (Deutsch and Gerard 1955). Perhaps because of an exposure to educational styles which emphasize the process of learning more than the content, the process of living is accepted as a goal in itself by the American student (Ruesch and Bateson 1968).

When a social responsibility is accepted by the individual-centered American, as it sometimes is, there is little feeling of being bound to complete actions designated in the commitment. Americans are low-context people, which means that they do not rely heavily upon their surroundings in the interpretations of their actions; this is in contrast to the Chinese, who are high-context people because of their reliance upon environmental influences in their social interactions. It has been shown that low-context people do not usually feel as bound to commitments 
as do those in high-context cultures (Hall 1977).

Such lack of commitment is reflected in many aspects of the educational system, structural as well as procedural. Students are not expected to commit themselves to a career-oriented course of study until many years into their educational experience. Once "committed," it is often easy--and even expected--that the choice will be changed. In upper divisions of the educational system, high school and college, it is not unusual for students to be allowed to change classes several weeks into their courses of study. Freedom of choice extends into the teaching process as we11, where students are encouraged to develop and change ideas, concepts and values as they progress along the educational trail. Growth is emphasized, with the result that change, too, is viewed as a desirable characteristic.

Mobility plays a responsible role in this change-oriented value structure. Students are moved from class to class, teacher to teacher and, often, school to school. Little is considered permanent. Students are expected to make new friends easily in their constantly changing environments and they learn to dispose of relationships as quickly as they initiate them. Social interaction is approached with gregarious superficiality. Sociability is defined as the establishment of smooth functioning relationships, maintaining a friendly front and low intensity, and avoiding deep involvement: the "stick-to-itiveness" that permeates the Chinese view of friendship and group loyalty is rarely found in American relationships (Ruesch and Bateson 1968). After a11, if other aspects of life lack permanence, why should personal commitment to a cause or a group be considered any differently? 


\section{DEMOCRACY}

The "other-directed" orientation of the Chinese that leads to their acceptance of authoritarianism is antithetical to the "inner direction," or self-reliance, of the Americans that leads to their democratic form of government and life-view (Hsu 1970). Delegation of authority and flexibility of status are necessary to the metropolitan, industrial and somewhat nomadic life of the American. In such a system authoritarianism would not easily fit. Americans view their form of government as a "situational" type of conformity, where submission to group opinion is not valued for its conformant qualities, but for the moral motive of equality of voice that it represents (Ruesch and Bateson 1968). In order to establish some form of workable government, the highly individualistic early Americans, not trusting each other with any more authority than they themselves possessed, implemented a system of checks designed to protect the rights of the individual while inherently sublimating these rights to group opinion.

This dedication to equality is found in the American custom of bringing those who have earned positions of authority back down to the common Teve1. To quote Juergen Ruesch (Ruesch and Bateson 1968, p. 107), "As soon as a man is labeled an authority, he becomes unequal and every + effort must be made to bring him back to the fold of the group and make him an equal again." Such a perception of equality puts the average American at ease: it is given a position of importance that exceeds even that of Tiberty, and great care is taken to make at least the outward appearance of the American society egalitarian (Ruesch and Bateson 1968).

Even before entering school American children are encouraged in a 
horizontal gravitation to peers that precedes their later conceptualization of equality and democracy. The American customs of providing cribs for babies and separate bedrooms for older children and the emphas is on peer associations are seeds for the generation gap which advances a disdain for authority (Hsu 1970). Such a disdain fosters a democratic approach to life.

The concept of democracy even finds its way into the comparatively authoritarian jurisdiction of the school. It is not unusual for teachers to allow students an occasional voice in the determination of their -activities, a voice quite often interpreted through the use of a majority vote. The democratically-oriented teacher may exhibit leadership techniques such as using frequent questioning, encouraging alternative solutions and approaches to problems, encouraging speculations from the group and generally lending a friendly atmosphere to the classroom situation. (Rosenfeld 1973). Students also participate in the democratic process through the extracurricular activities of electing class and club officers and voting in various types of social contests. An atmosphere of at least limited democracy pervades, the halls of most schools, bringing with it the promise of even more political voice for the students in the years to come.

Even what limited authoritarianism there is in the American educational system does not compare to the Chinese concept of it: in American + schools there is no really personal authority, only functional authority. It is the position that renders the power, not the person (Ruesch and Bateson 1968).

By its very nature the democratic process is a cous in to another dominant American characteristic, that of quantification; the voting 
process is definitely quantitative. This tendency is deeply rooted in American history, having at least partially originated from the pioneers' need to evaluate strangers quickly through easily identifiable means. Under such circumstances it was easy for "more" to be judged as "better." This disposition was further promoted by the whole economic trend of the Occidental culture--its emphasis on a monetary system (Ruesch and Bateson 1968).

American children begin early to learn the power of numbers (Hall 1977). They often hear their parents appraising them to others according to their size, intelligence, and the timing of their development process. Such a propensity towards quantification is perpetuated in the school system through grades, sports achievements and awards (Ruesch and Bateson 1968). Speed is often emphasized at the expense of accuracy (Klein 1956), encouraging the American student to guess the answers and to be less concerned about quality than quantity. The current popularity of speed reading is an excellent example of this American concern with haste. The characteristic of quantification, whether directly connected to that of democracy or considered on its own merit, is closely tied to the American preoccupation with competition. Most quantification is .... done with comparative measurement as its goal. Students learn that their grades are decided in relationship to other students; school athletes learn the importance of bettering the scores or records made by their teammates or competitors; placement of students in certain classes is often the result of test scores interpreted relative to the scores of others. The list goes on. The competitive spirit of the American individual is certainly fostered in the process of education (Hal7 1977). 
Unlike the Chinese, Americans tend to revel in direct confrontation. + One look at a couple of hours of American television violence is enough to convince even the most casual observer of this fact. The patient, nonaggressive Chinese would perhaps have difficulty coping with this aggressive and direct American approach.

Perhaps it is the lack of subtleties and intricacies in American interpersonal relationships that causes Americans to heed onty the most + obvious clues in their social interactions (Ruesch and Bateson 1968), therefore paying little attention to the feelings and thoughts of those they confront. This American characteristic has been politely referred to by those of more subtle cultures as "bluntness."

The American confrontation process may proceed in somewhat ritualistic stages: first there will be nonverbal cues that indicate disapproval or antagonism; if these fail to induce behavioral change in the person or persons to whom they are directed, the next step is a series of verbal hints, followed by verbal confrontation; when all else fails, the last dramatic step is one of either legal or physical action (Hall 1977).

It could be said that the action-oriented educational style of the American schools is responsible for promoting this value on confrontation. Through activities in the learning process students are encouraged to think in transitive terms and to have confidence in their ability to act on the people and things around them. The English language reflects this tendency, possessing a comparatively high percentage of transitive verbs. The school may also foster this penchant for active confrontation of issues through its encouragement of student exhibitionism. In 
practicing a newly acquired skill, the American students are often not only encouraged, but required to demonstrate their abilities in front of others (Ruesch and Bateson 1968). This type of behavior would be considered bad manners or "showing off" by those in many of the Eastern cultures.

Another factor to consider is the importance the educational system places on effort. Effort is considered equally as important as success (Ruesch and Bateson 1968). The old phrase, "an A for effort," certainly holds prominence in an American value system that was nurtured by the initiative and application of its pioneer forebearers. This attitude, a Tong with its adaptation, "There's no harm in trying," seems to value the active assertion of one's will in a way that has the potential of inflicting itself on the lives of others with little or no regard for the effect it may have on others (Ruesch and Bateson 1968).

Confrontation is activity, or achievement, and thus another link in the chain of characteristics which leads to the American competitive spirit. As in many of the sports activities that take place in the school environment, the American view of achievement is one of expediency -ri.e., the end justifies the means (Ruesch and Bateson 1968). Although on the surface this resembles the Chinese view of expediency, the difference lies in its manifestation--direct, active and goal-oriented confrontation. Whereas Chinese expediency is a process, American expediency is a product--a product of a competitive, individualistic society.

CRITICAL THINKING

While the basic need of a society like that of the PRC is one of 
control, a basic premise of a democratic society like that of the US is one of relative autonomy. While control is best nurtured through uniformity of ideas, the ideal of autonomy is dependent upon the diversity of ideas born from an analytical, critical thought process. While the development of a mechanistic memory is prevalent in the educational system of the PRC, in the US it is the development of critical intelli- gence and a self-regulating personality that receives attention in the schools (Gulick 1962).

The roots of such divergent approaches touch back on the values of conformity versus individuality, but it may be that there is another contributory factor to be considered as well. The US, since its founding, has been rich in subcultural variations, while the PRC, though possessing variations of its own, has subcultures that almost al7 stem from the same Eastern beginnings, giving them a commonality not present in all of the subcultures of the US.

When there are subcultural variations present in a society there is less likely to be uniformity in behavioral standards and less value is placed on this uniformity. Thus in the US much more so than in the PRC there is to be found fertile ground for independent and autonomous ideas (Ruesch and Bateson 1968).

One manifestation of this autonomy is the value placed on creativity + (Pepinsky 1961). American schools sometimes place more emphasis on the development of creative skills in all phases of learning--scientific, as well as literary and craft--than on the assimilation of information (Hsu 1970). It must be added, however, that there are bounds to this creative license: despite their respect for creative, original thought, Americans will tolerate it in moderate doses only, having little tolerance 
for its extremes. This perhaps explains why America is recognized for very few truly creative geniuses. One explanation proferred for this disparity in the attitude towards creative thought is that Americans are basicality afraid of the unpredictability and, thus, the insecurity produced by human differences (Ruesch and Bateson 1968).

Even after stripping away the extremes, Americans remain comparatively radical in their thought boundaries compared to the positivistic Chinese. American education relies on the unseen, the theoretical, unlike the Chinese reliance on the experiential and the empirical (Hsu 1970). Perhaps this explains why Americans are a low-context people and must rely more on words in the communication process, while the highcontext Chinese look towards their total communication experience for the interpretation of meaning.

American students learn independence of thought through encouragement to make their own decisions and to think things through for themselves. The democratic attitude towards authority contributes here through its encouragement of critical respect rather than unquestioning servility (Berg 1961). In the American way of thinking no one is immune from challenge; all people and ideas are open to analysis and criticism by colleagues, superiors and inferiors alike. This ideal dominates academic life.

The results of such analytical approaches to life are not always + positive. Because students are encouraged to consider both sides of issues, they may sometimes have trouble reaching decisions. It has also been shown that unstructured stimulus situations such as those present in the open-ended analysis style of American instruction may not follow normal probability distributions (Berg 1961), giving them a lack of 
predictability that can be unsettling to both students and teachers. Teachers' expectations of students' responses may also be higher than the actua? results received. Teachers expect students to understand what they have learned, a process which may be made even more difficult for the student because of the long, involved explanations necessary from the teacher (Ha11 1973).

Decision-making difficulties, lack of constancy in response and comprehension difficulties may all be carried by the students into the learning sets they use in their outside analyses.: Life's decisions may be made even more complex and seem even more insurmountable because of the complicated system of decision-making the students have come to know in the schools.

An even more significant result of this analytical patterning process is its effect on the conformant tendencies of individuals who are taught to use it. Several studies have shown that the more a person's problem-solving efforts are rewarded, the less he or she will tend towards conformant behavior (DiVesta 1959, MacBride 1958). Other related studies show how competency in problem-solving leads to a valuation of individual opinions over social ones (DiVesta 1959). Orientation towards creativity has also been associated with lesser amounts of conformity (Moeller and Applezweig 1957). The autonomy felt by the American student can be related to nonconformant behavior, for it has been shown that the more influence a person wields over others, the less conformant he or she will tend to be (Crutchfield 1955; Kelley and Volkart 1952; Tuddenham 1959). A relatively free-thinking student, then, would seem quite likely to develop the individualistic modes of thinking and perceptions so symbolic of the American way of Tife. 


\section{CONCLUSION}

The general theme that runs through the American characteristics of "self-orientation," "individual flexibility," "democracy," "confrontation" and "critical thinking" remains that of individualism and the accompanying inclination towards competition. In "self-orientation" one sees how physical and social isolation in educational practices fosters the individualistic, combative behavior that is reflective of the American society as a whole. In "individual flexibility" this competitive nature is related to the concerns of the society as a whole, with students, like their adult counterparts, protecting their individual concerns over the concerns of the group. The essence of "democracy" is the theoretically equal rights of all individuals, a factor which contributes to the fragmentation of people through the competitive, quantitative spirit it fosters. The American approach to "confrontation" is a further example of the aggressive, self-centered attitude learned in the schools-an attitude that also encourages an individual, competitive spirit. Finally, "critical thinking" is the ultimate in individualistic freedom, allowing for the diversity of thought that precedes diversity of action and concern.

Al1 of these American qualities point to the competitive tenor of American life. It is a value that is perpetuated through the process and structure of the educational system, and one that will manifest itself in all aspects of the communication processes to be discussed in the following chapter. 


\section{COMMUNICATOR STYLES OF THE CHINESE \\ AND AMERICANS IN A SMALL TASK GROUP SETTING}

The preceding chapters have demonstrated [how the general cultural values of the PRC and the US are perpetuated through their educational systems. A major portion of the paper has been spent on this aspect of the topic because such a background provides information crucial to the recognition and comprehension of cultural communication differences; the shifting of one's frame of reference necessary for true intercultural communication is made easier by such knowledge. A major premise of this paper is that this value perpetuation process tends to make the Chinese perceive life from a collateral, cooperative perspective and the Americans perceive life from an individualistic, competitive perspective. The ramifications of these two very different perceptual sets will now be described in relationship to communication styles in a small task group setting.]

Communication is an interchange of meanings among people that is only possible to the degree that the communicators have in common similar attitudes, desires and cognitions] (Krech, Crutchfield and Ballachey 1962). Without like experience levels, such commonalities are difficult to possess: the dynamic quality of communication is restrained at the boundaries of shared knowledge. This means that those from two such very different cultures as the Chinese and American may, because of their dissimilar backgrounds and perceptual sets, experience difficulties 
communicating with each other (Ruesch and Bateson 1968). Through the acculturation process they have come to expect to receive stimuli in ways which match the "sets" they have learned: when encountering interaction patterns which differ from those they anticipate, they may experience communication problems. Studies have supported this idea by demonstrating how moving from a familiar social setting to an unknown one produces uneasiness and lowered performance levels (Brembeck and Walker 1973). Once people have Tearned to perceive in a certain way it seems to be extremely difficult for them to adapt to new ways] (Hall 1973). Although cultural differences present a challenge to the communication process, this challenge can be met successfully. The solution lies, first of a11, in an awareness of what the differences are and why and how they operate. Such an awareness permits a certain amount of ability to overcome any difficulties the unfamiliar behavior may present to the communication process (Janis 1971).

[This next section will help to increase the possibility of predicting the communication behaviors of the Americans and the Chinese by describing what some of those behaviors may be in a small task group setting. So far this paper has dealt with three levels of reference--the environment, the group and the individual; it will now turn once again to the group, represented this time by the smal1 task group rather than by the larger educational group described earlier. Communication behaviors in the task, or goal-oriented, group wi11 be examined in the context of three categories of group process: operating variables, structural variables and interaction variables. These categories of variables interact with each other to make up the majority of the overt and covert factors functioning in the sma 1l. group communication process. Their application to the Chinese and 
American behavioral patterns, however, do not presume to be all-inclusive and inflexible: they are merely intended to present a basic overview from which additional research may spring. Although the variables presented will be specific to the American and Chinese cultures, as mentioned earlier, the process of relating them and analyzing their effects may be generalizable to other intercultural exchanges.

\section{OPERATING VARIABLES}

Operating variables are defined as those procedures, rules, norms and standards that facilitate the group process. They form the backbone of task group operations, for they regulate the tone and direction of the group's activities. In this category are included time, task and environmental factors that form the framework for group interaction (Rosenfeld 1973). Dịvisions of labor, leadership and member roles, and outcome analysịs are all important operating variables that will be examined here.

The individualistic personalities of Americans foster a group operational process that is as compartmentalized as is the American perceptual set: task group procedures are usually organized within a methodically segmented structure. Just as Americans have learned to perceive themselves as individuals separate from others and the environment, they tend to perceive all actions as discrete functions that must be organized and categorized. This is manifested in the task group through delegated divisions of labor (Davis 1969; Hal1 1977) and an emphasis on administrative details. Individual contributions are encouraged and initiative admired as work and action become the prerequisịtes of this methodical system. It has been said that when Americans 
are cornered or $i 11$ at ease they tend to fall back on details in their conversations and concerns (Ruesch and Bateson 1968). Such a preoccupation with the components of the whole rather than with the whole itself may stem not only from the American stress on individualism, but from the cognitive impersonality of the overall educational emphasis as well.] [Another manifestation of the American tendency towards organization is their linear, speed-conscious approach to time. They usually undertake tasks separately and in sequence, apportioning for accomplishment of each task a precise allotment of time. Schedules, either implicit or explicit, are an integral part of the American perception of 1 ife and, therefore, task group functions. This Tinear and segmented concept of time is referred to by $\mathrm{Hall}$ (1977) as "monochronic." \Such a concept contrasts with the Chinese view of time: in their more group-oriented, wholistic approach to life they tend to perceive task group operation in a more unified way, or from what Hall calls a "polychronic" time frame. They emphasize involvement and completion of the task over rigid, compartmentalized scheduling (Hall 1977). Like the "stream-of-consciousness" structure of their language (Cressy 1957), the Chinese see task completion as a flowing, centralized process to which all members contribute equally. The cooperative, groupcentered learning set formed in the educational process carries through to the Chinese perception of the operation of a group situation.

Despite this cohesive treatment of time organization, there is much concern with procedures and formalities in the Chinese task group (Kosokoff 1978). The concern lies more with the adherence to a superstructure of rules, regulations and customs that with an allotment of duties and schedules. The origin of this obsession may be found in the 
authoritarianism of the society. Those who have lived and learned under a stringent system of rules must come to expect a similar arrangement in all other activities. Although task group members usually function under a system slightly less restrictive than that with which they were educated--i.e., classroom hand-raising and other such external forms of discipline--they must still interact within a strongly maintained and regulated group structure] (Davis 1969).

[Just as Americans do not view themselves as responsible to universal causes and large groups, they are not as apt as the Chinese to feel a sense of obligation for the completion of task group procedures (Hall 1977). Group members may not feel bound to complete their actions if circumstances are not evolving sạtisfactorily for them. Even administratịve rules are subject to being readily scrapped or amended. This lack of loyalty and dedication is augmented by the generally accepted American code of expediency which says that the end justifies the means (Ruesch and Bateson 1968). Clearly it is the individual rather than the group who holds the final say in the formation of and adherence to the standards of the group's operationg

[The Chinese, on the other hand, are subject to the cohesiveness of their upbringing: they will tend to adhere more faithfully to the norms of the group, regardless of their personal feelings. This has the cyclical effect of increasing the already present cohesiveness of the group (Hall 1977), since norms are essential to its maintenance.

Task outcome, àn extremely important variable in task group analysịs, may aịso tend. to be regarded differently by the Americans and the Chinese. In a society as concerned with numbers as America, it is not surprising that results are often measured quantitatively rather 
than qualitatively (Ruesch and Bateson 1968). Americans rely on graphs, surveys, and other numerical measurements to tell them how successful they have been. As the Chinese strive for modernization, they, too, may soon gravitate towards such determinations of accomplishment; for the time being, however, a preoccupation with quantity over quality would be seen to be inconsistent with the Maoist philosophy that promotes mastery rather than superficial quantities of knowledge.

In order to survive the intercultural interaction process that must occur if two such divergent structures come together, the Chinese and the Americans wịl need to be constantly aware of and patient in response to each other's perception of organization. Americans may have to put asịde some of their zeal for haste and schedules, while the Chinese may need to organize themselves in a more compartmentalized fashion. This would especially require great patience on the part of American business people, who tend to be among the most intense when it comes to time schedules and delegation of duties. The Henry Ford philosophy of assembly-line efficiency may have to be modified to fit a slightly less frantic approach. Change on either side will not be easy to accomplish, for it involves stepping completely out of a familiar perceptual framework and into an alien one. Through the process of empathic awareness, however, it can be done. Furthermore, it must be done if Americans and Chinese are to work together in the future--whether in task group situations or in any other way.

STRUCTURAL VARIABLES

Structural variables in task group operation are those that affect the group's communication and attraction networks. Here it is important 
to establish the communication patterns and subgroup formations and the effects that these have on social, emotional and task group development (Rosenfeld 1973).

[Structural variables are especialty different in the Chinese and American small group situations because of their different perceptions of group government. The Chinese, being oriented towards authoritarianism with normally follow a more rigid and centralized interaction pattern, white the democracy-oriented Americans will tend to follow a more individualistic pattern. Cooperative and competitive instincts are 7argely responsible for such divergent perceptions of group operation: the cooperative nature of the Chinese makes it possible for the group to function smoothly under authoritarian rule; the competitive nature of the Americans makes it necessary for every group member to have a somewhat equal voice in the management of group functions. These differences dramatically affect the interaction patterns of the groups.

In American task groups, although there may be a principal leader of the group, the leader's authority, like that of the classroom teacher discussed earlier, is functional rather than inherent. His or her control is limited to a facilitative role, making the leader basically dependent upon the group for approval. Leaders are expected to guide rather than direct (Ruesch and Bateson 1968). Democratic leaders encourage group members to coordinate and evaluate the group's actions; they pose more questions than other types of leaders and they encourage alternate approaches to the tasks at hand (Rosenfeld 1973). They are kept humble by the democratic decision-making process that allows group members to question authority. In a highiy homogeneous group, in fact, any exertion of authoritarian opinions or statements is likely to be 
rejected by the rest of the group (Bass 1961). In such groups it is also possible that rather than their being one leader, a great many group members may perform the leadership function, thus further decentralizing any potential power structure (Kwal and Fleshler 1971). The basic American attitude towards leadership, whether in the classroom, politics or the small task group, is one of critical respect, not one of unquestioning servility (Pepinsky 1961).

[The people of the PRC, having been conditioned to respond, for the most parta unquestioningly to authority, naturally tend to expect to grant their leaders the cooperation their American counterparts discount. The historically ingrained tolerance for ambiguity possessed by most. Chinese is best suited for a hierarchy-oriented group experience. Very seldom, if ever, would there be no leader at all (Kosokoff 1978). Group leaders, who are usually appointed by someone higher up in the organizatịonal structure, are accorded deference and respect (Danton 1938). All other members of the group are generally considered to be of equal status (Campbell 1961), a factor that contributes to the cohesiveness with which they gravitate towards the central figure of the leader.] [This latter characteristic means that it would be to and from the leader that most final communications would be made. Authoritarian: leaders assume the major responsibility for directing, coordinating and evaluating the group's activities. They are usualiy more concerned than democratic leaders with the group's productivity. They may manifest their concern with control by attempting to answer themselves many of the questions posed within the group (Rosenfeld 1973). ]

[In the more democratic American group, a] though the leader may serve as a structural force in the communication network, communications 
flow more frequently among the other members of the group than in the Chinese group. Lines of communication may be found nearly equally dispersed through all of the possible group configurations, instead of consistently funneling through the group leader. With less centralized leadership there is apt to be a greater feeling of participation and responsibility among the group members (Hsu 1970)]

[The communication network is not only visible in the interaction patterns of the group, but through nonverbal signals as well. Depending on the facilities and circumstances, of course, American and Chinese sma11. groups may arrange themselves in a variety of revealing formations. Those Chinese small groups observed were usually arranged in a circular seating configuration, unlike the more rigid row organization of classrooms. The circle is certainly reminiscent of the cohesive, groupcentered Chinese personality. In relationship to the Chinese view of authority, there mịght seem to be a discrepancy here, if it were not for the fact that the leader, the authority figure, is given slightly more space to accord him or her the appropriate status. The leader is even given authority over the space of others: the Chinese assign to a "fixed feature" category such items as chairs, which they may not move without the permission of their leader (Hall 1973). ]

TThe use of a circular seating arrangement and the general Tack of overt manifestations of authority in a Chinese group situation may be due to the fact that it is less necessary to use noticeable displays of command in a culture where authority is inherently accepted. There is a dichotomy here: the leader must superficially appear to be a part of the group, but authority is affirmed by the less visible centralization accomplished through the communication network. 
The American leader, not being so inherently established in the authority position, may find it necessary to display authority through external means, such as sitting at the head of a rectangular table. This procedure is being changed, however, in many organizational groups, with the leader often positioning himself or herself in the middle of the table or perhaps using a cjrcular table, in order to reassert the effect of being one of the group.

Being task specialists, American leaders are less motivated to receive positive affective responses from group members; they are more likely to criticize and categorize them, thus establishing the individual alienation process covertly as well as overtly (Rosenfeld 1973).

The formation of subgroups is more likely to occur in American task groups than in the chinese, due to the segmentation tendencies of individualistic groups. A cohesive group will be more likely to work together, thus avoiding splinter social and task subgroups. The effect of such unity is to further increase cohesiveness; conversely, the effect of segmentation is to further decrease cohesiveness, since subgroups can be detrimental to group functioning (Rosenfeld 1973).

The wide differences in structural variables in American and Chinese groups may indeed be some of the most fundamentally difficult to surmount: these differences touch upon the very heart of the perceptual dissimilarities of the two cultures, their individualistic and groupcentered orientations. It may be extremely challenging for Americans to put aside their feelings for individual rights in order to function within the authoritarian structure of a Chinese task group and, conversely, difficult for the group-centered Chinese to accommodate themselves to a more individualistic form of group government. In either 
case it would once again mean stepping out of one's perceptually conditioned frame of reference and into that of another.

\section{INTERACTIVE VARIABLES}

[The personality traits, attitudes, beliefs and self-concepts which individuals bring into a group situation combine to produce certain affective and problem-solving skills termed "interactive variables" (Rosenfeld 1973). Considered within the framework of this study, whose main purpose is one of determining interactive tendencies, this set of variables is significant. The cooperative Chinese value system and the competitive American value system have direct effects on the ability of their respective task groups to work together and to solve problems.

Partially because of their conformant tendencies, Chinese group members will generally interact-in a- fessmbold and overt fashion than will American. Throughout numerous studies conformant personalities have been shown to exhibit interpersonal communication qualities that superficicially appear less aggressive, impulsive and self-confident than their more independent counterparts (Beloff 1958; Hochbaum 1954; Hovland, Janis and Kelley 1953; Mouton, Blake and 01mstead 1956). They tend, therefore, to be more submissive and dependent. Such inclinations manifest themselves in behaviors that may seem $\operatorname{cool}$ and reserved to the more outgoing Americans. Although the physical arrangement of Chinese group members may, through its proximity, outwardly indicate intimacy, generally other overt displays of affection are avoided (Nahirny 1962). It has been suggested that one of the interesting features of close ideological groups such as the communist organization of the PRC is that displays of personal affection are vehemently opposed 
because of their inhibiting effect on devotion to the political cause. To counteract this scarcity of physical expression, the Chinese have developed an ability to quickly internalize feelings of fellowship with strangers who share their same ideals (Nahirny 1962).

Americans, on the other hand, are considered quick to display closeness, even though it may be only on a superficial level. Their individualịtịc and competitive spirits have given them an interactive style that appears self-reliant and autonomous (Hsu 1970). They are gregarious, needing to ascertain and continualiy reaffirm their acceptance by the group. This factor is perhaps a result of the feeling of separateness that their individuality imposes upon them. Within the task group superfịcial friendliness is illustrated by a quick use of first names and a generally overt sense of familiarity. Americans tend to be casual in their approach to others, even strangers, and their language, both verbal and nonverbal, reflects this informality. Human relationships are quickly initiated and easily dissolved (Ruesch and Bateson 1968), reflecting a basic indifference towards and an avoidance of deep involvement with group members. This may at least partially be due to their necessary response to change in a society where children learn young that relationships are so often only temporary.

To compensate for the feeling of isolation that individuality and self-reliance may bring, Americans often attempt to enhance their individual positions in the group by acting in a way that will give them status. This results in a competition with other group members as they all vie for attention in various ways. The competitive spirit is divisive in its effect upon the interaction process. Group members often mistrust each other (Ruesch and Bateson 1968): they never know when 
another group member, in a similar quest for status, may act in such a way as to diminish their own importance. Under extremely competitive situations, group members may even withhold necessary information from each other, thus impeding progress towards task completion. All such behaviors serve to diminish the amount of interaction in the group (Kleị 1956).

This difference in intensity between the more externally expressive Americans and the more internal Chinese also relates to a difference in the kinds of communicative behaviors used. As mentioned earlier, the Chinese are more "high-context" communicators and the Americans more "low context." The Americans, tending to be superficial communicators, rely upon words and other overt behaviors to express their ideas, whereas the Chinese emphasize the context in which something is said or done. The Chinese depend little on the coded or explicit part of messages and instead look to nuances and implicit meanings (Hall 1977). Words are used sparingly, clichés frequently summing up ideas with an economy of expression (Danton 1938). Such a paucity of language extends to facial movement: the Chinese are known for not showing their emotions in easily visible ways. To the uninformed American this may be viewed as part of the stereotypical "inscrutability" of the Oriental culture. The Chinese may, in turn, find the more explicit and overt displays of Americans to be obnoxiously self-centered.

The Chinese propensity towards subtlety extends into conflict situations. Chinese students learn conflict avoidance early in life, and they bring this knowledge to the small group interaction process. In troublesome situations it is considered better to act as though nothing has happened, therefore avoiding the inevitability of action that would 
be necessitated by acknowledgement ( $\mathrm{Ha} 11$ 1977). If, however, it does become necessary for a group member to reveal displeasure with another, any reproach is enacted implicitly in the subtleties of behavior rather than blatantly exposed. To avoid loss of face, compromise is used whenever possible. As mentioned previously, the Chinese view truth and action as pragmatic: courtesy and face must be preserved even at the cost of what an American might term as personal integrity. Outspoken Americans will especially have difficulty coping with this cultural difference if they are not aware of its causes and implications.

Americans working in task group situations with the chinese might tend to insist upon certain courses of action only to find that they gain nothing by doing so. Aggressive behavior which overlooks the Chịnese value on face may end all fruitful communication on the spot. If, on the other hand, Americans offer the Chinese a compromise situation, they may gain more than originally expected. Once trust has been established in this type of an intercultural relationship, the Chinese will generally go out of their way to work with the Americans (Danton 1938). There is a tendency to come to the aid of those in whom they have confidence (Cressy 1957), and they will demonstrate their sense of group-oriented generosity in such a relationship. Because of this generosity, less information will be withheld in a Chinese task group setting, and the resultant cooperative mood allows them to learn more from each other than their competitive American counterparts (Deutsch and Gerard 1955).

Despite the fact that Americans are known to be forthright in their confrontations with others, when working in a small group setting this trend is usually tempered by decorum. It almost seems that group members 
are not quite free to speak their minds. They may exhibit a reluctance to make flat statements in the areas of opinion or policy and avoid direct confrontation with other group members whenever possible (Ruesch and Bateson 1968). Much of the anxiety present under such inhibiting circumstances is exhibited through nonverbal rather than verbal signs. This may be due to a fear of self-disclosure or of appearing foolish, which relates back to the American students' reluctance to answer questions in class for fear of being ridiculed if wrong. The fear of losing the competitive social game is still very much present in the adult American.

The actual decision-making process in an American task group setting pairs 211 of the interpersonal skills mentioned above with related patterns of interaction. Competitive American group members generally approach problems from an analytical, critical and individualistic standpoint, while the cooperatively-oriented Chinese generally approach them from a coordinated, conforming standpoint (Krech, Crutchfield and Ballachey 1962). The shared frame of reference resulting from this latter standpoint makes the accomplishment of task goals easier.

The interdependence of Chinese group members leads to uniformity of opinion and susceptibility to manipulation by the group leader (Krech, Crutchfield and Ballachey 1962). Leaders, though characteristically avoịding direct commands and statements (Danton 1938), expect group members to concede to their wishes. Deviant members will be subtly persuaded to conform with the desires of the group. A study by Back (1951) showed that the more cohesive a group, the greater potential it has for effecting change in the behavior of the group members. Directly opposite to this tendency is the American propensity towards nonconformity. The low interdependence of American group members tends to make them 
less subject to group coercion (Krech, Crutchfield and Ballachey 1962). For the Chinese to expect compliance to group or leader decisions when interactịng with Americans, then, would be a mistake.

The only form of coercion, subtle though it may be, that may aid the Chinese in coping with what they may feel is uncooperative behavior on the part of an American would be to use a rational argument. Americans pride themselves on being efficiently logical. The achievement-oriented American personality attacks most tasks from a problem-solving approach, aiming towards making decisions quickly and easily, a trait which is culturaliy perpetuated in the educational practice of approaching learning from a problem-solving, critical position. Because of this bent towards Togic, Americans are apt to appear coldiy business-7ike and single-mindedly devoted to only the task at hand. Although they like to emphasize creative solutions to problems, their slim tolerance for extreme originality prevents them from having any great propensity for idiosyncratic problem solutions (Ruesch and Bateson 1968).

Because in an authoritarian society there is a smaller number of choices to be made, Chịnese task groups are able to solve problems quickly (Klein 1956). It has been shown that cooperative groups will have a higher degree of productivity in terms of both quantity and quality of output than competitive groups (Deutsch and Gerard 1955). They also invest more effort in the maintenance and regulation of the group structure. It is the very cooperative nature of the group that gives it this additional strength: a study of the effect of cooperation on task performance showed that this effect is interactive--i.e., the overall effect is greater than the sum of all individual efforts because of the 
contributory force that each individual effort has on the efforts of the others (Davis 1969).

On the other hand, another study (McCurdy and Lambert 1952) showed that individuals tend to make fewer mistakes than groups, indicating perhaps that the more individualistic problem-solving approach of the Americans is in some ways beneficial to the goals of the group. The study specifically tested the efficiency of small groups of three compared to individuals working on problems that required a great deal of cooperation. It also found no difference in efficiency between $\therefore$ groups in which free communication was allowed and those in which an appointed leader made a 71 the decisions, two cases which somewhat mirror the circumstances of the US and the PRC. Another study (Marquart 1955) found that the group is seldom better than the best individual in that group, further saying that in many cases the apparent superiority of a group may result from the presence of one superior individual.

Whether it is the individualistic or the group-centered task group that is judged to be superior in efficiency really does not matter during an intercultural communication encounter between the two. What matters is that the groups recognize their interactive differences and attempt to work with them. Americans must be aware of the fact that Chinese group members will interact in subtier ways than those to which they are accustomed, that "face" must be maintained at al1 times, and that the decision-making and interactive processes will be more centralized than their own democratic system. The Chinese must be aware of the fact that American group members are more overt and often superficial in their communications, that they tend to deal more directly with problems and that their interactions reflect a democratic, individualistic perception 
of life. Each group must not only recognize these differences, but seriously try to interpret all behavior within the appropriate framework, adjusting their own behaviors accordingly. 
CHAPTER XII

SUMMARY AND CONCLUSIONS

\section{SUMMARY}

This paper has attempted to bring together a large and diverse body of information regarding the cultures of the United States and the People's Republic of China; it has then focused its attention on the transferrence of this cultural data to the people, through the acculturation processes of their formal education systems, and on the resultant general effect on communication behaviors. These behaviors were examined in the context of the small task group setting, a setting which is felt to have significance in the upcoming relations between the two countries.

This paper has established that knowledge of the value systems of a culture is essential in understanding the communication behaviors of each culture, for values have a definite impact on the direction of courses of action.

It has also established that value systems are learned, not inherited, Because of the large amount of time spent in formal education systems, the schools of the US and the PRC must accept a major portion of responsibility for the perpetuation of cultural values. Through those stimuli, both implicit and explicit, which exist in the educational setting, students form perceptual and learning sets which dictate the manner in which they receive and interpret all other stimuli. This process, called "deutero-learning," serves to perpetuate the values of 
the culture: basic, learned perceptual sets will not significantly diminish as students become adults--adults who are teachers, administrators, parents, leaders or followers and who, therefore, influence the perceptual sets of new generations, making the cycle complete.

That is not to say that the cycle is unbreakable and without variations. It is, in fact, a belief in perceptual flexibility that has led to the writing of this paper, for without the ability to. step out of one's perceptual sets one would never be able to communicate effectively with those who perceive life differently. It is essential that such an ability be developed, for when the members of two such diverse cultures as those of the US and the PRC come together in a task group setting they will be bringing with them all of their perceptual and learning sets, and those sets will dramatically affect the success of their communications. Before true communication can take place, each group member must understand what those sets are and why and how they operate.

What are those perceptual and learning sets in the US and the PRC? In examining the general characteristics of the cultures, two basic perceptual themes dominate: for the US it is an individualistic, competitive set, and for the PRC it is almost exactly the opposite-a collateral, cooperative set. Each of these general characteristics is encouraged through the educational structures and processes of their respectịve countries.

The educational system of the PRC takes a collateral approach in the classroom through its almost exclusive tendency to emphasize group activities. This can be observed in such areas as instructional techniques, nonverbal classroom stimuli and reward systems, as well as in a stress on mutual responsibility. The opposite, a self-oriented 
approach, is found in American classroom procedure, where individuality is encouraged through an emphasis on the unique needs and achievements of each child.

In the Chinese educational system the concept of social responsibility is also emphasized. This is done through blending politics with instruction. The American students, on the other hand, feel little dedication to commitments or causes in a learning environment that is based on the principles of flexibility and detachment.

The authoritarianism of the communist government is reflected in their educational system: an other-directed, vertical orientation is fostered through a teacher-centered classroom. The horizontal orientatịon of a democratic form of government is to be found in the American classroom, where extra-curricular as well as curricular activities generally rely on democratic procedures, a characteristic which promotes in Americans a quantitative perceptual set.

The less aggressive nature of the Chinese is reflected in the use of confict avoidance in their educational environment: positive behavior is emphasized and "face" is maintained, creating a harmonious educational atmosphere that would be quite foreign to the more actionoriented and aggressive American students.

The Chinese government attempts to control the behaviors of their citizens through an equalizing and regulatory process. Such a process is promoted in the classroom through lowered admission standards, an emphasis on rote learning and reciting, and the requirement that all students spend some time working with the peasants in the fields and factories. The regulatory tone of the Chinese system would seem alien to Americans, for they are taught to approach learning from a critical, 
analytical and somewhat creative standpoint.

All of the above have been shown to result in the aforementioned perceptual and learning sets of individualism and competition and collaterality and cooperation. These sets were suggested in the communication behaviors of the two cultures as they affected the operational, structural and interactive variables present in a small task group.

Those variables found in the American task group are: a stress on organization, task accomplishment, and democratic group organization and leadership; a monochronic time orientation; a lack of commitment to group objectives; a quantitative approach to solutions; an analytical, somewhat creative approach to problem-solving; and outspoken, aggressive and superficially gregarious oral communications.

Those variables present in the Chinese task group are: an interdependence of group members; a concern with formality and procedure; a polychrnoic time orientation; a strict adherence to group norms; minimal overt dịsplays of emotion or censure, as manifested in a concern for "face," indirection and compromise; directive leaders; a centralized communication pattern; a conformant decision-making process; an efficient problem-solving approach; and a high dependence on context for the interpretation of messages.

\section{CONCLUSIONS}

There are no fancy tricks involved in the process of overcoming the communication barriers induced by such very different perceptual and learning sets as those existing in the American and Chinese cultures. The solution is very simple: One must first define those differences and their manifestations, as this paper has attempted to do; then, using 
this information as a guide, one must attempt to transcend the bounds of one's own perceptual set and to experience--intellectually and emotionally--the interaction through the perceptual set of the other.. This is where simplicity can be deceiving, for the empathic skills required for the latter step come more easily to some than to others. The solution may be simple, but it is not always easy.

If one cares enough to make this effort, however, it can be done. Caring is an essential ingredient of intercultural communication, for caring is involvement and involvement is the crux of the empathic process. If one attempts to truiy listen to others--not just with the ears, but with the whole being, mind and body; if one avoids evaluative and critical responses, trying not to view each issue as a "win-10se" proposition; and if one interprets all interactions within this open-minded framework...then perhaps true intercultural communication can take place.

As relations between the US and the PRC continue to build, such intercultural communication skills will become not just desirable, but crucial. It is not just in this way that the skills are needed, however: they are needed in every aspect of life, as the peoples of the world increasingly come into contact with others whose value systems and communication behaviors are different from their own. This may mean others from foreign cultures and ethnic groups, or simply others who look at life from a slightly different perspective. The word "communication" is related to the word "commune" and implies a sense of community with fellow human beings (Rosenfeld 1973). Intercultural communication extends that community just one step further into the community of the world. 


\section{SUGGESTIONS FOR FURTHER RESEARCH}

The ideas proposed in this paper suggest several interesting topics for further empirical research: although much cultural and historical data is already available on both the US and the PRC, there is always room for additional analyses of these areas; the field of deuterolearning ịs relatively young and unexplored and certainly deserves further investigation; and the field of empathy, also well documented (for further information, refer to Milton Bennett's "Overcoming the Golden RuTe: Sympathy and Empathy." Ed. P. Nimmo. Communication Yearbook 3. International Communication Association, 1979), continues to call for exploration of its application to various situations.

Most relevant at the present, however, would be research addressing the interaction processes of a small task group consisting of Americans and Chịnese. In light of today's increasing contact between the cultures of the US and the PRC, it would seem to be especially important to test the validity of some of the individual behavioral patterns suggested in this paper and to examine their effects within an intercultural exchange --more specifically, the effects that some of the cultural differences have on contract negotiations between the two countries.

Since operating variables are the ground rules for the interaction process, it is especially desirable that several cultural differences present in this area be explored. How, for example, will efficiencyminded Americans interact within the less urgent atmosphere of the Chinese task group? Will the Americans measure task outcomes differently than the Chinese? What about closure: how will the expectations of each cultural group affect task completion? Will there be a difference 
in the times that each group perceives closure taking place?

This paper's exploration of task group structural variables implies some deeply rooted differences between the cultures of the US and the PRC. Given the dissimilarities in leadership expectations--i.e., authoritarian versus democratic--it would be interesting to explore their effects on group interaction and task completion. Would discrepancies in expectations interfere with cohesion? And, if so, how? What kinds of leadership and interaction styles can the American business person adapt to best fit into the Chinese authoritarian system? Perhaps most productive would be a content analysis of the general interactive network of a group containing a mixture of Chinese and Americans. One could examine the network in several situations: with an American leader, with a Chinese leader, with a predominant number of Americans, with a predominant number of Chinese, and so forth.

The section of this paper dealing with interactive variables also suggests several provocative ideas for further study. What, for example, is the effect of the American-style gregariousness on the more reticent Chinese, and vice versa? This question could be explored in relationship to cohesiveness, group effectiveness or perception of others. A representation of this latter question may be found in nonverbal communication: how accurately do the more high context Chinese perceive the nonverbal communications of the Americans? Does the low context American sharpen his or her nonverbal abilities when put into contact with the less verbal Chinese?

Each of the three communication areas explored in this paper-operating, structural and interactive variables--offers much material for further exploration, and it is hoped that this study has provided 
an impetus for such investigation. Knowledge of the field of interaction between the US and the PRC is in its modern infancy; many of the previous assumptions are no longer valid and it is necessary to explore this area anew. 
Back, K.W. "Influence through Social Communication." Journal of Abrormal Social Psychology, 46 (1951), pp. 9-23.

Barry, H. "A Test for Negativism and Comp1iance." Journal of Abnormal Sociàl Psychology, 25 (1931), pp. 373-389.

Bartlett, F.C. 'Remembering. Cambridge: Cambridge University Press, 1932.

Bass, Bernard M. "Conformity, Deviation, and a General Theory of Interpersonal Behavior." In Conformity and Deviation.

Ed. Irwin A. Berg and Bernard M. Bass. New York: Harper and Brothers, 1961, pp. 38-100.

Bateson, Gregory. Social Planning and the Concept of "Deutero-Learning." Conference on Science, Philosophy and Religion. Second Symposium. New York: : Harper, 1942.

........ "Cultural Determinants of Personality." In Personality and the Behavior Disorders. New York: Ronald, 1944, pp. 714-733. VoT. II.

Beloff, H. "Two Forms of Social Conformity: Acquiescence and Conventionality." Journal of Abnormal Social Psychology, 56 (1958), pp. 99-104.

Berg, Irwin A. and Bernard M. Bass, ed. Conformity and Deviation. New York: Harper and Brothers, 1967.

Bion, W.R. Experiences in Groups and Other Papers. New York: Basic Books, 1959.

Blake, Robert R. and Jane Srygley Mouton. "Conformity, Resistance and Conversion." In Conformity and Deviation. Ed. Irwin A. Berg and Bernard M. Bass. New York: Harper and Brothers, 1961, pp. 1-37.

Blau, Peter M. Exchange and Power in Social Life. New York: John Wiley and Sons, Inc., 1964.

Bormann, Ernest G. Discussion and Group Methods:- Theory and Practice. New York: Harper and Row, 7969.

Brameld, Theodore. Cultural Foundations of Education. New York: Harper and Brothers, 1957. 
Brembeck, Cole S. and Walker H. Hill, ed. Cultural Challenges to Education. Lexington: Lexington Books, $1 \overline{973 .}$

Campbe11, Donald T. ":Conformity in Psychology!s Theories of Acquired Behavior.". In Conformity and Deviation. Ed. Irwin A. Berg and Bernard M. Bass. New York: Harper and Brothers, 1961, pp. 101-142.

Cartwright, Darwin and ATvin Zander, ed. Group Dynamics. New York: Harper and Row, 1968.

Chan, Itty. "Head Start in the Socialist Way." New China. Jan. 1976.

China: AClàss by Itself. NBC News Specia1. 11 Jan. 1979.

"Chịnese Tells of hịs Uncertainty about Perfection of Marxism." Seattle Times, 22 Jan. 1979, Sec. A, p. 11.

Chu, Godwin C. Ràdical Change through Communication in Mao's China. Honolu?u: - The University Press of Hawaii, 1977.

The Committee of Concerned Asian Scholars. China! Inside the People's Republic. New York: Bantam Books, 1972.

Coser, Lewis A. The Functions of Sociàl Conflict. Glencoe: Free Press, 1956.

Cressy, Earl Herbert. Understanding China. New York: Thomas Neison and Sons, 1957.

Crittenden, Brian. Education and Socià Ideà7s. Canada: Longman Canada, Ltd., 1973.

Crutchfield, R.S. "Conformity and Character." American Psychologist, 10 (1955), pp. 197-798.

Danton, George H. The Chinese People. Boston: Marshall Jones Co., 1938.

Davis, James H.' Group Performance. Reading, Massachusetts: AddisonWesley Publishing Co., 1969.

Dennịs, Wayne. "CuTtural and Developmental Factors in Perception." In Perception: An Approach to Personality. Ed. Robert R. Blake and GTenn V: Ramsey. New York: The RonaTd Press Co., 1957.

Deutsch, M. and H.B. Gerard. "A Study of Normative and Informational Social..Influences upon Individual Judgment." Journal of Abnormal Social Psychology, 51 (1955), pp. 629-636.

DịStefano, M.K. Jr. "Changes in Success-Failure Attitudes During Adolescence." Journàl of Genetic Psychology, 116, No. 1 (1970), pp. $17-13$. 
DiVesta, F.j. "Effects of Confidence and Motivation on Susceptibility to Informational Sound Influence. Journal of Abnormal Social

Psychólogy, 59 (1959), pp. 204-209.

"Educational Policy: Questions and Answers." Peking Review. 14 April 1978, pp. 13-15.

Epps, Edgar G., ed. 'Cultural Plüalism. Berkeley: McCutchan Publishing Corp., 1974.

Faust, W. "Group Versus Individual Problem Solving." Journal of Abnormal and Social Psychology, 59 (1959), pp. 68-72.

Fearing, F. and E.M. Krise. "Conforming Behavior and the J-Curve Hypothesis." Journal of Social Psychology, 44 (1941), pp. 109-118.

Gamberg, Ruth. Red and Expert. New York: Schocken Books, 1977.

$\therefore$ Gibson, Eleanor J. Principles of Perceptual Learning and Development. New York: Meredith Corp., 1969.

Goleman, Daniel. "Breaking Out of the Double Bind." Psychology Today, August 1978, pp. 43-51.

Grossack, M.M. "Some Effects of Cooperation and Competition upon Smal1 Group Behavior." Journà] of Abnormà Social Psychology, 49 (1954), pp. 341-348.

Guilick, Sidney Lewis. The East and the West. Rutland, Vermont: Charles E. Tuttle Co., 1962 .

Gupte, Ramesh S. "The Political Thought of Mao Tse-tung." International Behavioral Scientist, 2" (1970), pp. 47-64.

Ha11, Edward T. The Silent Language. New York: Anchor Books, 1973.

-...n....... Beyond Culture. New York: Anchor Press/Doubleday, 1977.

Hare, Paul A. Sma71 Group Research. New York: The Free Press of Glencoe, T962.

Harlow, H.E. "The Formation of Learning Sets." Psychology Review, 56 (1949), pp. 51-65.

Harvey, 0.J. and J. Rutherford. "Relationship of Status in the Informal Group to Influence and Influencibility at Differing Age Levels." Tech. Rept. 3, Contract NONR 2149(02), Group. Psychology Branch, Office of Naval Research, (undated).

Hevi, Emmanual John. An African Student in China. New York: Frederick A. Praeger, 1963. 
Hilgard, Ernest R, "The Role of Learning in Perception." In Perception: An Approach to Personality. Ed, Robert R. Blake and Glenn V. Ramsey. New York: The Ronald Press Co., 1951.

-....... Theories of Learning. New York: Appleton-Century-Crofts, Inc., 1955 .

Hochbaum, G. "The Relation Between Group Members' Self-Confidence and their Reactions. to Group Pressures to Uniformity." American Sociology Review, 19 (1954), pp. 678-687.

Hovland, C.I., I.L. Janis and H.H. Kelley. Communication and Persuasion. New Haven: Yale University Press, 1953.

Hsu, Francis L. Americans and Chinese. New York: The Natural History Press, 1970.

Ichheiser, G. "Misunderstandings in Human Relations." American Journal of Sociology, 55, Part 2 (Sept. 1949).

Isenberg, Irwin, ed. 'Chinaa: New Force in World Affairs. New York: H.W. WiTson Co., 7972 .

Janis, Irving L. "Groupthink." Psychology Today, Nov. 1971, pp. 43-46, pp. $74-76$.

Kelley, H. and E. Volkart. "The Resistance to Change of Group-Anchored Attitudes." American Sociology Review, 17 (1952), pp. 453-465.

Kelman, H.C. "Effects of Success and Failure on 'Suggestibility' in the Autokinetic Situation." Journal of Abnormal Social Psychology, 45 (1950), pp. 267-285.

Kimbal1, Solon T. "The Transmission of Culture." In Schooling in the Cultural Context. New York: David McKay Co., 1976.

KTeịn, Josephine. The Study of Groups. London: Routledge and Kegan PauT, Ltd., $7 \overline{956 .}$

KTuckhohn, Clyde and Henry Murray, ed. Personality in Nature, Society and Culture. New York: Alfred A. Knopf, 1949.

Kosokoff, Steve. Department of Speech Communication, Portiand State University. Personal Interview. 23 July. 1978.

Krebs, A.M. "Two Determinants of Conformity: Age of Independence Training and Achievement." Journal of Abnorma? Social Psychology, 56 (1958), pp. 130-131.

Krech, David, Richard S. Crutchfield and Egerton L. Ballachey. Individual in Society. New York: McGraw-Hill Book Co,, Inc., 1962. 
Kwa 1, T. and H. Fleshler. "Self-Concept and Leadership Behavior." Paper presented at the Speech Communication Association Annual Convention. San Francisco, Dec. 1971.

Lefkowitz, M., R:R. Blake and Jane S. Mouton. "Status Factors in Pedestrian. Kiolation of Traffic Signals." Journal of Abnormal Sociál Psychology, 51 (1955), pp. 704-706.

Lehmann, Winfred P. 'Language and Linguistics in the People's Republic of China. Austin: University of Texas Press, 1975.

Linton, Ralph. The Cultural Background of Personality. New York: D. Appeiton-Century Co., Inc., 1945.

MacBride, P.D. "The Influence of Confidence upon Resistance to Perceptual Judgments to Group Pressure." Technology Report 4, Contract NONR 171-055, Princeton University, 1958.

Malinowski, Bronislaw. "The Psychology of Sex and the Foundations of Kinship in Primitive Societies." Psyche, 4 (1923-1924), pp. 98-129.

Marquart, Dorothy I. "Group Problem Solving." Journal of Social Psychology, 41 (1955), pp. 103-113.

Martinda7e, Don. American Society. New York: D. Van Nostrand Co., Inc., 1960.

Maskerras, Colin and Neale Hunter. 'China Observed. London: Pall Mall Press, 1968.

Mausner, B. and B:L. Boch. "A Study of the Additivity of Variable Affecting Social Interaction, "Journal of Abnormal Social Psychology, 54 (7957), pp. 250-256.

McCurdy, H.G. and W.E. Lambert. "The Efficiency of Small Human Groups in the Solution of Problems Requiring Genuine Cooperation." Journal of Personality, 20 (1952), pp. 478-494.

Miller, N.E. and J. Dollard. Social Learning and Imitation. New Haven: YaTe University Press, 1941.

Moeller, G. and M.H. Applezweig. "A Motivational Factor in Conformity." Journa 7 of Abriorma 7 Socià 7 Psychology, 55 (1957), pp. 174-120.

Mouton, J.S., R.R. Blake and J.A. 0lmstead. "The Relationship Between Frequency of Yielding and the Disciosure of Personal Identity." Journal of Personality, 24 (1956), pp. 339-396.

Myrdal, Jan. Report from a Chinese Village. New York: Pantheon Books, 1965.

Nahirny, VTadimir. "Some Observations on Ideological Groups." American Journat of Sociology, 67 (1962), p. 398. 
Nakamura, Hajime. The Ways of Thinking of Eastern Peoples. Japan: Printing Bureau, Japanese Government, 1960.

Needham, Joseph. Science and Civilization in China. With the research assistance of Wang Ling. Cambridge: University Press, 1954-1976.

Newcomb, Theodore M. The Acquaintance Process. New York: Holt, Rinehart and Winston, 1961.

Newcomer, Jim. "What are Today's China and its People Really Like? Nation Reaches New Era, Quality of Life Refreshing." The Sunday Oregonian, 18 June 1978, Sec. B, p. 1.

Parsons, T. The Social System. Glencoe, Illinois: Free Press, 1951.

Pepinsky, Pauline Nichols... "Social Exceptions that Prove the Rule." In Conformity and Deviation. Ed. Irwin A. Berg and Bernard M. Bass. New York: Harper and Brothers, 1961, pp. 380-411.

Ramịrez, Manuel and Douglass Price-Williams. "Ethnic Differences in Delay of Gratification." Journal of Social Psychology, 93, No. 1 (June 1974), pp. 23-30.

Rich, John Martin. Humanistic Foundations of Education. Worthington, Ohio: Charles A. Jones Publishing Co., 1971.

Roberts, Joan... and Sherrie. K. Akinsanya. Educational Patterns and Cultural Configurations. New York: David McKay Co., Inc., 1976.

Rosenfeld, Lawrence B. Human Interaction in the Sma11 Group Setting. Columbus, Ohio: Charles E. Merrill Publishing Co., 1973.

Rosenthal, Ted L. and Barry J. Zimmerman. Social Learning and Cognition. New York: Academic Press, 1978.

Ruesch, Jurgen, M.D. and Gregory Bateson. Communication: the Social Matrix of Psychiatry. New York: W.W. Norton and Co., Inc., 1968.

Sagan, Carl. The Dragons of Eden. New York: Ballantine Books, 1977.

Scott, S.A. "Factors Affecting the Learning of Personal Values Through Social Reinforcement." American Psychologist, 71 (1956), pp. 407409.

Sega 17, Marshal7 H., Donald T. Campbe11 and Melville J. Herskovits. The Influence of Culture on Visual Perception. New York: Bobbs Merri77, 1966.

Seligman, C.G. "The Vision of the Natives of British Guinea." In Report of the Cambridge Anthropological Expedition to Torres Straits. VoT. II. Ed. A.C. Haddon. Cambridge: Cambridge Unịversity Press, 1901. 
Shepherd, Clovis R. 'Small Groups: 'Some Sociological Perspectives. San Francisco: Chandier, 1964.

STosson; E.E. "A Classroom Demonstration of Suggestion." Psychology Review, 6 (1899), pp. 407-408.

Spring, Joe1. 'American Education. New York: Longman Inc., 1978.

Steiner, I.D. and S.C. Peters. "Conformity and the A-B-X Model." Journal of Personality, 26 (1958), pp. 229-242.

Thibaut, John W. and Harold H. Kelley. The Social Psychology of Groups. New York: John Wiley, 1959.

Tregear, T.R. The Chinese: How They Live and Work. New York: Praeger Publishers, 1973.

Tuddenham, R.D. "Correlates of Yielding to a Distorted Group Norm." Journal of Personality, 27 (1959), pp. 272-284.

"Visionary of a New Chịa." Time. 1 Jan. 1979, pp. 12-20.

Wenburg, John R. and William W. Wilmot. The Personal Communication Process. New York: John Wiley and Sons, Inc., 1972.

Witkin, Herman .A...."A Cognitive Style Approach to .Cross-Cultural Research." International Journal of Psychology, 2, No. 4 (1967), pp. 233-251.

Wïtkin, H. et al. 'Psychological Differentiation. New York: Lawrence Erlbaum Associates, 1974.

Woodside, ATexander Barton. Vietnam and the Chinese Model. Massachusetts: Harvard University Press, 1971.

Yen, Maria. The Umbrella Garden. New. York. The MacMillan Co., 1954.

Yu, Frederick T.C.' Mass Persuasion in Communist China. New York:

Frederick A. Praeger, 1964. 